\title{
Metabolomic Evaluation of Ralstonia solanacearum Cold Shock Protein Peptide (csp22)-Induced Responses in Solanum lycopersicum
}

\author{
Dylan R. Zeiss, Paul A. Steenkamp, Lizelle A. Piater and lan A. Dubery*
}

Department of Biochemistry, Research Centre for Plant Metabolomics, University of Johannesburg, Auckland Park, South Africa

\section{OPEN ACCESS}

Edited by:

Marnix H. Medema,

Wageningen University and Research,

Netherlands

Reviewed by:

Ric C. H. De Vos,

Wageningen University and Research,

Netherlands

Tri Rini Nuringtyas,

Gadjah Mada University, Indonesia

${ }^{*}$ Correspondence:

Ian A. Dubery

idubery@uj.ac.za

Specialty section:

This article was submitted to

Plant Metabolism

and Chemodiversity,

a section of the journal

Frontiers in Plant Science

Received: 27 October 2021 Accepted: 13 December 2021

Published: 07 January 2022

Citation:

Zeiss DR, Steenkamp PA,

Piater LA and Dubery IA (2022)

Metabolomic Evaluation of Ralstonia

solanacearum Cold Shock Protein

Peptide (csp22)-Induced Responses

in Solanum lycopersicum.

Front. Plant Sci. 12:803104.

doi: 10.3389/fpls.2021.803104
Ralstonia solanacearum, the causal agent of bacterial wilt, is one of the most destructive bacterial plant pathogens. This is linked to its evolutionary adaptation to evade host surveillance during the infection process since many of the pathogen's associated molecular patterns escape recognition. However, a 22-amino acid sequence of $R$. solanacearum-derived cold shock protein (csp22) was discovered to elicit an immune response in the Solanaceae. Using untargeted metabolomics, the effects of csp22-elicitation on the metabolome of Solanum lycopersicum leaves were investigated. Additionally, the study set out to discover trends that may suggest that csp22 inoculation bestows enhanced resistance on tomato against bacterial wilt. Results revealed the redirection of metabolism toward the phenylpropanoid pathway and subbranches thereof. Compared to the host response with live bacteria, csp22 induced a subset of the discriminant metabolites, but also metabolites not induced in response to $R$. solanacearum. Here, a spectrum of hydroxycinnamic acids (especially ferulic acid), their conjugates and derivatives predominated as signatory biomarkers. From a metabolomics perspective, the results support claims that csp22 pre-treatment of tomato plants elicits increased resistance to $R$. solanacearum infection and contribute to knowledge on plant immune systems operation at an integrative level. The functional significance of these specialized compounds may thus support a heightened state of defense that can be applied to ward off attacking pathogens or toward priming of defense against future infections.

Keywords: cold shock protein, defense, elicitor activity, hydroxycinnamic acids derivatives, metabolomics, phenylpropanoids and phenolics, plant immunity activation

\section{INTRODUCTION}

The immobile nature of plants exposes them to an environment filled with a diverse range of biotic-and abiotic stimuli and stressors. Since plants are the primary producers within most food systems, they are threatened by bacteria, fungi, viruses, insects, and herbivores. Plants synthesize a large variety of surface-located receptors that allow them to interact with the surrounding environment and defend themselves from unavoidable threats (Ranf, 2018; Malik et al., 2020). Plant innate immunity is thus reliant on cell-autonomous events, with these events displaying an overlapping similarity when compared to the immune system of animals. To compensate for the absence of an adaptive immune system, plants have evolved a greater pathogen recognition 
capacity (Freeman and Beattie, 2008; Dodds and Rathjen, 2010). The described pattern recognition receptors (PRRs) recognize and bind to molecules deemed foreign or non-self to the host (Sanabria et al., 2012), defined as microbial-associated molecular patterns (MAMPs). Exposure of the plant to a live pathogen would expose it to a consortium of different MAMPs, with different chemical signatures originating from peptide, carbohydrate and lipid-based structures (Boller and Felix, 2009; Sanabria et al., 2012). This results in the initiation of intracellular signaling cascades leading to a plant immune response in support of a broad-spectrum resistance that limits pathogen ingress and development (Malik et al., 2020). The perception of the MAMP molecules functions as an early warning system against pathogens and allows the rapid activation of the plant defense mechanisms.

The causal agent of the bacterial wilt disease, Ralstonia solanacearum, is regarded amongst the most destructive bacterial pathogens due to several behavioral, geographic and host factors (Mansfield et al., 2012). The disease has been difficult to contain due to the pathogen's ability to evade host recognition. A contributing factor to the pathogen's success would be that many of the prototypical MAMPs described in literature are not perceived by host plants (Wei et al., 2018) allowing the pathogen to successfully infiltrate the host by bypassing many of the pre-existing defense mechanisms. For example, the polymorphic flagellin-derived flg22 sequence from R. solanacearum (flg $22^{\mathrm{Rso}}$ ), elicits no response in tomato (Wei et al., 2018, 2020), which sets back the development of strategies to limit the bacterial wilt disease.

However, the discovery of the cold shock protein (csp)derived csp22 elicitor, reported to induce an immune response in several species of the Solanaceae, together with its corresponding PRRs, has opened new avenues of scientific exploration in the Solanaceae. The csps of bacteria are defined by intracellular hyperaccumulation in response to rapid temperature fluctuations of $>10^{\circ} \mathrm{C}$ to assist with the challenges faced by the microorganism; which includes the rigidification of the cell membrane, inefficient protein folding, as well as a decreased efficiency in transcription and translation (Keto-Timonen et al., 2016; Wang et al., 2016). The highly conserved nucleic acid binding motif RNP-1 of csps (the 22-amino acid core or csp22) was found to function as MAMPs and to selectively induce immune responses in species belonging to the Solanaceae family (Zipfel, 2014; Wang et al., 2016). Initially, the phenomenon that Solanaceae plants possess an immunological detection method directed at the perception of membrane impermeable proteins naturally found in the cytoplasm of bacteria (as also applies to elongation factor $\mathrm{Tu}$ ), came as a scientific mystery, and suggested the presence of a PRR for csp recognition located at the plant cell surface (Wang et al., 2016). The PRR of Solanum lycopersicum was identified by mapping the natural variation in csp22 perception between S. lycopersicum and S. pennelli and was named the cold shock protein receptor (CORE) (Wang et al., 2016; Wei et al., 2018). Similarly, in Nicotiana benthamiana, the PRR responsible for csp22 perception was named as the receptorlike protein required for csp22 responsiveness (NbCSPR). This PRR was found to associate with the brassinosteroid insensitive 1 (BRI1)-associated kinase upon elicitor treatment to confer bacterial resistance in an age-dependent and flagellin-induced fashion (Saur et al., 2016). These studies also underlined the biotechnological potential to augment immunity and defense by interspecies transfer of CORE/CSPR to other plant families (Wang et al., 2016).

This observation motivated for the investigation of downstream metabolic processes following csp22-elicitation in order to evaluate the functional significance of adaptive metabolome changes. In terms of "omics" levels, metabolomics is the final manifestation of integrated upstream biological information flow and thus the determinant of the eventual phenotype. Integration of data originating from metabolomics with transcriptome and/or proteome data offers gene-tometabolite and protein-to-metabolite analysis in support of reliable understanding and interpretation of metabolism. Here, we monitored the effects of csp22-elicitation on S. lycopersicum using an untargeted metabolomics approach. Additionally, the study set out to discover trends that may indicate that csp22 treatment confers increased resistance to $R$. solanacearum in S. lycopersicum. Metabolomic analyses have shown potential in studies involving plant-pathogen interactions by revealing subtle metabolic alterations in response to biotic or abiotic perturbations and can subsequently be regarded as an adequate method of functionally investigating plant metabolism (Tugizimana et al., 2018; Zeiss et al., 2018, 2019; Castro-Moretti et al., 2020).

\section{MATERIALS AND METHODS}

\section{Plant Cultivation}

Seeds from the tomato cultivar, "Star 9001" was obtained from a tomato breeding program for resistance against $R$. solanacearum (Stark Ayres, Pty. Ltd., Bredell, South Africa) ${ }^{1}$ and cultivated in germination mixture (Culterra, Muldersdrift, South Africa). Plants were grown under greenhouse conditions: a light/dark cycle of $12 \mathrm{~h} / 12 \mathrm{~h}$, with the light intensity set at $80 \mu \mathrm{mol} / \mathrm{m}^{2} / \mathrm{s}$ and the temperature regulated to between 22 and $24^{\circ} \mathrm{C}$. Plants were rotated on a daily basis to prevent any positional effects.

\section{csp22 Peptide}

The csp22 peptide elicitor with sequence ATGTVKWFNETKGFGFITPDGG (Wei et al., 2018), was synthesized at $\geq 90 \%$ purity (GL Biochem, Shanghai, China). A stock solution of the peptide elicitor was made to $1 \mathrm{mg} / \mathrm{mL}$ in $8 \mathrm{mM} \mathrm{MgSO}$ and used as a diluted sample during the inoculation procedures.

\section{DAB Histochemical Staining}

The leaves of $6 \mathrm{w}$ old mature tomato plants were treated with csp22 and subsequently stained with a 3,3'-diaminobenzidine (DAB, Sigma, St. Louis, United States) solution to visualize and detect the presence of hydrogen peroxide $\left(\mathrm{H}_{2} \mathrm{O}_{2}\right)$. The protocol was performed with slight modifications as previously described (Bach-Pages and Preston, 2018). Briefly, the abaxial side of the

\footnotetext{
${ }^{1}$ www.starkeayres.co.za
} 
leaves were treated with $500 \mathrm{nM}$ csp22 by means of pressure infiltration and incubated for $30 \mathrm{~min}$. The corresponding abaxial side of the leaves were treated with $8 \mathrm{mM} \mathrm{MgSO}_{4}$, which served as a negative control. Care was taken to avoid excess wounding or mechanical damage during pressure infiltration. The DAB solution ( $1 \mathrm{mg} / \mathrm{mL}$ in water, $\mathrm{pH} 3.8$ ) was prepared $1 \mathrm{~h}$ before use. The leaves were excised from the plant and placed within a DAB solution under light at $23^{\circ} \mathrm{C}$ for $8 \mathrm{~h}$ with constant agitation. After the incubation period, the leaves were removed and immersed in boiling $70 \%$ ethanol for $10 \mathrm{~min}$. After cooling, the leaves were transferred into absolute ethanol at room temperature and left overnight. The leaves were then imaged. The visible brown polymerized precipitate in the host tissue was produced as a result of the oxidation of DAB by $\mathrm{H}_{2} \mathrm{O}_{2}$.

\section{Oxidative Burst Luminescence Assay}

Leaf disks $\left(0.4 \mathrm{~cm}^{2}\right)$ were punched out from fully expanded leaves using a cork borer. The leaf disks were floated adaxial side up on $200 \mu \mathrm{L}$ MilliQ water in a white 96-well microtiter plate (Nunc, Roskilde, Denmark) which was placed under light at room temperature for $24 \mathrm{~h}$. After the incubation period the water from each well was completely removed and replaced with a $100 \mu \mathrm{L}$ of a master mix solution composed of: $34 \mu \mathrm{g} / \mathrm{mL}$ luminol (Sigma, St. Louis, United States) and $20 \mu \mathrm{g} / \mathrm{mL}$ horseradish peroxidase (Sigma, St. Louis, United States) and $1 \mu \mathrm{M} \operatorname{csp} 22$ in $8 \mathrm{mM} \mathrm{MgSO}_{4}$. Special consideration was taken to limit mechanical damage of the leaf disks during the floating disk and water removal steps. A negative control composed of the abovementioned master mix, excluding the csp22 elicitor, was added. The negative control was supplemented with $8 \mathrm{mM} \mathrm{MgSO}_{4}$ to maintain sample volumes. Luminescence was measured every 2 min for 60 min using a Synergy HT Biotek microplate reader (Biotek Instruments, Vermont, United States). The luminescence data was exported to an excel file for further analysis. To account for natural variability three leaf disks per plant were taken. In total of 24 leaf disks were used per treatment condition.

\section{Plant Elicitation and Experimental Design}

Six-week-old tomato plants were watered generously $5 \mathrm{~h}$ prior to elicitor inoculation to open leaf stomata and facilitate inoculation. Three plants, selected for uniform size and appearance, were reserved for each treatment/control condition prior to the treatment process. To ensure sample consistency, leaves from the fourth node branching point of the plants were selected for elicitor/control inoculation. The respective plants were treated with $(500 \mathrm{nM})$ elicitor solution by pressure infiltration into the leaves using a blunt-ended syringe. Separate plants were treated with $8 \mathrm{mM} \mathrm{MgSO}_{4}$ functioning as a negative control. In each instance, the entire leaf surface was supplied with elicitor/control treatment solution to minimize biological variation. It should though be noted that the fragility and complex reticulate venation inherent with tomato leaves complicate the inoculation process and that care should be taken to avoid/limit wounding or mechanical damage. After inoculation, the plants were incubated for 16,24 , and $32 \mathrm{~h}$, respectively. After each incubation time the inoculated leaves were harvested from the three selected plants, snap-frozen in liquid nitrogen to quench metabolic activity and stored at $-80^{\circ} \mathrm{C}$ until further use. The experimental design consisted of three biological replicates $(n=3)$ that were created for each elicitor/control treatment at each time point $(16,24$, and $32 \mathrm{~h})$, thus constituting 18 biological sample groups $(3 \times 2 \times 3)$ in total, covering all conditions.

\section{Metabolite Extraction}

The leaf tissues frozen with liquid nitrogen were pulverized with a mortar and pestle. Two grams of leaf powder were extracted with $80 \%$ methanol in a $1: 10(\mathrm{w} / \mathrm{v})$ ratio. The samples were sonicated twice in a sonicator bath for $30 \mathrm{~min}$, with the temperature controlled at $20^{\circ} \mathrm{C}$. Cell debris was pelleted with a bench top swinging-bucket centrifuge set at $5,525 \times \mathrm{g}$ and $5^{\circ} \mathrm{C}$ for $20 \mathrm{~min}$. The supernatants were evaporated to $1 \mathrm{~mL}$ using a rotary evaporator at $55^{\circ} \mathrm{C}$, carefully transferred into $2 \mathrm{~mL}$ microcentrifuge tubes and dried in a heating block overnight at $55^{\circ} \mathrm{C}$. The samples were then reconstituted in $500 \mu \mathrm{L}$ of $50 \%$ HPLC-grade Methanol: MilliQ water solvent (1:1, v/v). The 18 samples were filtered through $0.22 \mu \mathrm{m}$ nylon syringe filters into vials fitted with $500 \mu \mathrm{L}$ inserts and stored at $4^{\circ} \mathrm{C}$ until analyzed. Three pooled quality control (QC) samples consisting of aliquots of all samples, as well as 50\% methanol blanks were included in the sample list. The QC samples were added to check sample stability, feature legitimacy, assess intensity drifts that occur during data the acquisition process, and monitor instrumental efficiency and robustness. Each of the 18 biological samples (that were prepared in triplicate as biological repeats) were analyzed in triplicate (technical repeats) on the UHPLC-MS instrument to gain precision and accuracy. Although the method described above has been widely used in scientific metabolomics literature, it should be noted that the extraction of highly polar compounds e.g., phosphates and sugars, highly non-polar compounds e.g., several lipid and sterol species, as well as volatile compounds may only partially extract or not at all. There are currently no extraction method that can recover the entire metabolome with a high level of robustness and reproducibility (Tugizimana et al., 2013). Previous literature has shown that the described method is able to recover many of the secondary metabolites of interest present within the tomato metabolome (Gómez-Romero et al., 2010; Roldan et al., 2014).

\section{Ultra-High Performance Liquid Chromatography Coupled to High Definition Mass Spectrometry}

Two microliter of each sample extract was analyzed on an UHPLC-quadrupole time-of-flight (qTOF) high-definition MS system equipped with an electrospray ionization (ESI) source (Synapt G1, Waters Corporation, Manchester, United Kingdom). The analytes were separated on an Acquity HSS T3 reverse-phase column $(2.1 \times 150 \mathrm{~mm} \times 1.7 \mu \mathrm{m}$; Waters Corporation, Milford, MA, United States) using a binary solvent system consisting of acetonitrile (Romil Chemistry, Cambridge, United Kingdom): MilliQ water, with both solvents containing $0.1 \%$ formic acid (FA, Sigma, Munich, Germany) and 2.5\% isopropanol (Sigma, Munich, Germany). A gradient elution method was used over a $30 \mathrm{~min}$ run with a flow rate set to $0.40 \mathrm{~mL} / \mathrm{min}$. The elution was started at $2 \%(\mathrm{v} / \mathrm{v})$ acetonitrile from 0 to $1 \mathrm{~min}$, 
raised to $70 \%$ acetonitrile from 1 to $22 \mathrm{~min}$, taken up to $95 \%$ from 22 to $23 \mathrm{~min}$ then kept constant at 95\% acetonitrile from 23 to $26 \mathrm{~min}$. The composition of the mobile phase was then reverted to $2 \%$ acetonitrile from 26 to $27 \mathrm{~min}$, for column cleaning and equilibration from 27 to $30 \mathrm{~min}$. The chromatographically separated metabolites were detected with the aid of a SYNAPT G1 high definition mass spectrometer (Waters Corporation, Manchester, United Kingdom) set to acquire data in both positive and negative ionization modes. The MS conditions were as follows: capillary voltage of 2.5 $\mathrm{kV}$, sample cone voltage of $30 \mathrm{~V}$, microchannel plate detector voltage of $1,600 \mathrm{~V}$, desolvation temperature of $450^{\circ} \mathrm{C}$, source temperature of $120^{\circ} \mathrm{C}$, cone gas flow of $50 \mathrm{~L} / \mathrm{h}$, desolvation gas flow of $550 \mathrm{~L} / \mathrm{h}, \mathrm{m} / \mathrm{z}$ range of $50-1,500$, scan time of $0.2 \mathrm{~s}$, interscan delay of $0.02 \mathrm{~s}$, mode set as centroid. The lockmass flow rate was $0.1 \mathrm{~mL} / \mathrm{min}$, with leucine encephalin as reference calibrant $(50 \mathrm{pg} / \mathrm{mL},[\mathrm{M}+\mathrm{H}]+=556.2771$ and $\left.[\mathrm{M}-\mathrm{H}]^{-}=554.2615\right)$, continuously sampled every $15 \mathrm{~s}$, producing an average intensity of 350 counts/scan in centroid mode, with typical mass accuracies between 3 and $5 \mathrm{mDa}$ and a mass accuracy window of $0.5 \mathrm{Da}$. High purity Helium was used as desolvation-, cone-, and collision gas. The MS analyses performed in an unfragmented as well as four fragmenting experiments $\left(\mathrm{MS}^{\mathrm{E}}\right)$ simultaneously using ramping of the collision energy from 10 to $50 \mathrm{eV}$. The data acquisition at these collision energies was used to facilitate metabolite fragmentation and ease downstream structure elucidation and compound annotation. Each of the three biological replicates was analyzed in triplicate on the UHPLC-MS system, creating the technical replicates $(n=3)$. Thus, data for nine samples were obtained $(n=9)$ that was further processed by multivariate data analyses (MVDA).

\section{Metabolomics Data Processing and Analysis}

The UHPLC-ESI-MS data sets were analyzed with Masslynx $\mathrm{XS}^{\mathrm{TM}}$ software (Waters Corporation, Manchester, United Kingdom), with the addition of other statistical programs for MVDA. The raw UHPLC-ESI-MS data was processed with MarkerLynx XS ${ }^{\mathrm{TM}} 4.2$ software, with the following parameters: 0.60-21 min retention time (Rt) range of the chromatograms and $m / z$ domain of mass range $50-1,500 \mathrm{Da}$. The Rts were allowed to differ by $\pm 0.20 \mathrm{~min}$ and the $\mathrm{m} / z$ values by \pm 0.05 $\mathrm{Da}$. The mass tolerance was $0.01 \mathrm{Da}$ and the intensity threshold was 10 counts. Only the data matrices with noise level less than 50\% (MarkerLynx cut off) were retained for downstream data analyses. The MarkerLynx application uses the patented ApexPeakTrack algorithm to perform accurate peak detection and alignment. Furthermore, MarkerLynx performs sample normalization, based on total ion intensities of each defined peak. Prior to calculating intensities, the software performs a modified Savitzky-Golay smoothing and integration (Zhou et al., 2012; Chen et al., 2013; Tugizimana et al., 2016).

The generated data matrices were imported into SIMCA (soft independent modeling of class analogy) software, version 14.0 software with the "omics" skin (Sartorius Stedim Data Analytics AB, Umeå, Sweden) for statistical analyses. To put all variables on equal footing, and adjust for measurement errors, the Pareto-scaling method was applied to data prior to chemometric modeling. A non-linear iterative partial least squares algorithm (built-in the SIMCA software) was used to handle missing values, with a correction factor of 3.0 and a default threshold of 50\%. Unsupervised and supervised learning methods were applied. As part of the unsupervised methods, both principal component analysis (PCA) and hierarchical cluster analysis (HiCA) were applied. PCA is an unsupervised projection-based statistical method, used for reducing the multi-dimensionality of the data matrix. This is done by projecting the data matrix into lower dimensional space (2D) where global and qualitative visual representation of the observations can be observed. This results in the discovery and summarization of underlying clusters, trends, or sample outliers, as well as displaying the systematic variation present within the data matrix. Orthogonal projection to latent structures discriminant analysis (OPLS-DA modeling), as the chosen supervised method and binary classifier, was applied as the variable selection method to compare the samples of the elicitor treatment to that of the $\mathrm{MgSO}_{4}$ controls-leading to identification of metabolite features positively correlated to the discrimination between the two groups (Tugizimana et al., 2013). The OPLS-DA separates multivariate relationships into predictive (positively correlated to the csp22-treatment) and orthogonal (positively correlated to the control) variation. As a tuning procedure in computing the models, a sevenfold crossvalidation (CV) method was applied (Tugizimana et al., 2016). Thorough model validation steps were consistently applied; and only statistically valid models were examined and used in data mining for metabolite annotation. For variable selection, the OPLS-DA loading S-plots were used. The loading plot displays an S-shape when the data is centered and Paretoscaled. The loadings plot facilitates the identification of features with variability between groups (discriminating variables), i.e., variables situated at the upper right or lower left sections in the S-plot. Discriminant features with a $\mid p$ (corr) $\mid$ of $\geq 0.5$ and a co-variance value of $|(\mathrm{p} 1)| \geq 0.05$ were selected for further analysis (Trygg et al., 2007). It should be noted that these selection parameters are largely data dependent. These selection parameters were chosen based on the application of descriptive statistics (ANOVA) to the downstream metabolite features, where a statistical cut-off of $p$-value $<0.05$ was used. To avoid selection bias, the statistical significance of each potential marker was investigated with the application of univariate descriptive statistics. These analyses included the generation of average intensity values, standard deviations, $p$-values, fold changes, and each feature's coefficient of variation in control and treatment samples. The overall selectivity of the OPLS-DA models was assessed by constructing receiver operating characteristic (ROC) curves. The ROC curves illustrated the supervised model's ability to discriminate between features correlated to the different sample conditions. The predictive capacity of the supervised models was assessed with a $n=100$ response permutation test. The permutation test consisted of comparing the $Q^{2}$ obtained for the original data with the distribution of the $Q^{2}$ values calculated during the randomly assigned permutations (Triba et al., 2014). 


\section{Annotation of Metabolites}

The chemical-and structural identities of the metabolites were elucidated using their respective mass spectral properties and patterns obtained during the MS analyses. MS spectral-based metabolite identification was performed based on sufficient and accurate mass fragment information, accurate calculation of each feature's elemental composition and database searches for possible metabolite annotation. MassFragment, a built in Markerlynx software tool, was utilized for assigning possible structures to observed fragment ions of the precursor metabolite features using novel algorithms. The putative empirical formula of each statistically significant extracted ion peak (XIC) in the mass spectra was obtained and searched in databases (ChemSpider, ${ }^{2}$ Dictionary of Natural Products, ${ }^{3}$ PubChem, ${ }^{4}$ the KEGG Compound database, ${ }^{5}$ and Metacyc $^{6}$ database for the identification of possible compound matches (Gómez-Romero et al., 2010; Mhlongo et al., 2016; Zeiss et al., 2018). The analysis and identification of lipids was facilitated using the Lipidmaps database. ${ }^{7}$ Metabolites were annotated and tentatively identified to level 2 of the Metabolomics Standards Initiative (MSI) (Sumner et al., 2007; Spicer et al., 2017).

\section{RESULTS}

The experiments were set up in such a way that the leaf tissues of the "Star 9001" tomato cultivar were pressure infiltrated with the $R$. solanacearum-derived csp22 peptide-the MAMPperceived component of bacterial cold-shock proteins-and appropriately harvested at selected incubation time points, i.e., 16,24 , and $32 \mathrm{~h}$ post inoculation. The "Star 9001" cultivar was selected due to: (1) its apparent disease resistance toward $R$. solanacearum (Zeiss et al., 2018), as well as (2) minimal venation patterns present on the abaxial side of the leaves, which facilitated the pressure infiltration process. The research followed an untargeted metabolomics workflow to detect the elicitorinduced perturbations and subsequent metabolic patterns within the metabolome of $S$. lycopersicum that could be interpreted as a positive correlation toward a conferred resistant phenotype against $R$. solanacearum.

\section{Reactive Oxygen Species Production and Oxidative Burst}

The DAB staining protocol was performed, as a qualitative validation method, to verify that the elicitor was perceived by the plant and that a defense-related physiological response was triggered. The left abaxial side of the leaves was treated with the elicitor solution, while the right abaxial half was supplied with the $\mathrm{MgSO}_{4}$ control. The formation of a color product (Figure 1A) revealed the presence of $\mathrm{H}_{2} \mathrm{O}_{2}$ and associated

${ }^{2}$ www.chemspider.com

${ }^{3}$ https://dnp.chemnetbase.com/

${ }^{4}$ http://pubchem.ncbi.nlm.nih.gov/

${ }^{5}$ https://www.genome.jp/kegg/compound/

${ }^{6}$ https://metacyc.org/

${ }^{7}$ https://www.lipidmaps.org/
ROS. The associated production of ROS in planta hints to the trigger of the oxidative burst and suggests the activation of initial plant immune responses. The time-dependent kinetics of the elicitor-linked oxidative burst was investigated using the chemiluminescence assay (Figures $\mathbf{1 B}, \mathbf{C}$ ). Univariate statistics were applied, in the form of a Student's $t$-test, to determine the statistical significance $(P \leq 0.0001)$ between the two conditions. The data generated from the DAB stain and chemiluminescence assay confirmed the plant's ability to perceive of the csp22 peptide elicitor. This is in contrast to the non-perception of the polymorphic flg22 from $R$. solanacearum, regarded as part of the pathogen's immune evasion strategy (Wei et al., 2018, 2020).

\section{Chromatographic Separation and Mass Spectrometric Detection of Metabolites}

As an analytical platform, reverse-phase UHPLC-MS is especially suitable to reflect the overall phytochemical abundance of plants, including secondary/specialized metabolites which have a defensive or protective function (Tugizimana et al., 2013). Following leaf inoculation, harvesting and metabolite extraction with $80 \%$ methanol (able to extract a wide range of semi-polar and non-polar metabolites), the sample extracts were analyzed on such a high definition/accurate mass UHPLC-MS system. The base peak intensity (BPI) chromatograms highlighted the relative peak intensities and adequate resolution of individual peaks as well as the increased ionization of S. lycopersicum metabolites in ESI negative mode (Figure 2). Qualitative variation is reflected by the peak size-where the $\mathrm{y}$-axis represents the relative intensity of metabolites on the $\mathrm{x}$-axis at their respective Rts (min). Changes in peak intensities and/or the presence/absence of peaks reflect differential variation in csp22-induced leaf metabolism. A comparison of the chromatograms between the control and treated conditions highlights the induced metabolic perturbations over the described incubation points in the $20 \mathrm{~min}$ Rt window (Figures 2A,B).

\section{Data Analysis and Statistical Modeling}

Multivariate data analysis was performed as the chosen method of data exploration by: (1) revealing trends within the metabolome across the incubation time points, and (2) detecting similarities/differences in the metabolite profiles of the treatment conditions. Processing of the chromatographic data yielded a data matrix containing the relative intensities of detected metabolite features (variables) present in each of the samples (observations). The data matrix was subjected to PCA (Figure $\mathbf{3 A}$ - an unsupervised projection-based statistical method, used for reducing the multi-dimensionality of the data matrix. By projecting the data embedded in the matrix into lower dimensions (2D), a global and qualitative visual representation of the observations can be observed-leading to the discovery and summarization of underlying clusters, trends, or sample outliers, thus displaying the systematic variation present within the data matrix. Additionally, the data matrices were subjected to HiCA (Figure 3B), an unsupervised hierarchical-based statistical method that was used complimentary to PCA. HiCA was performed: (1) to build a hierarchy of the sample observations 

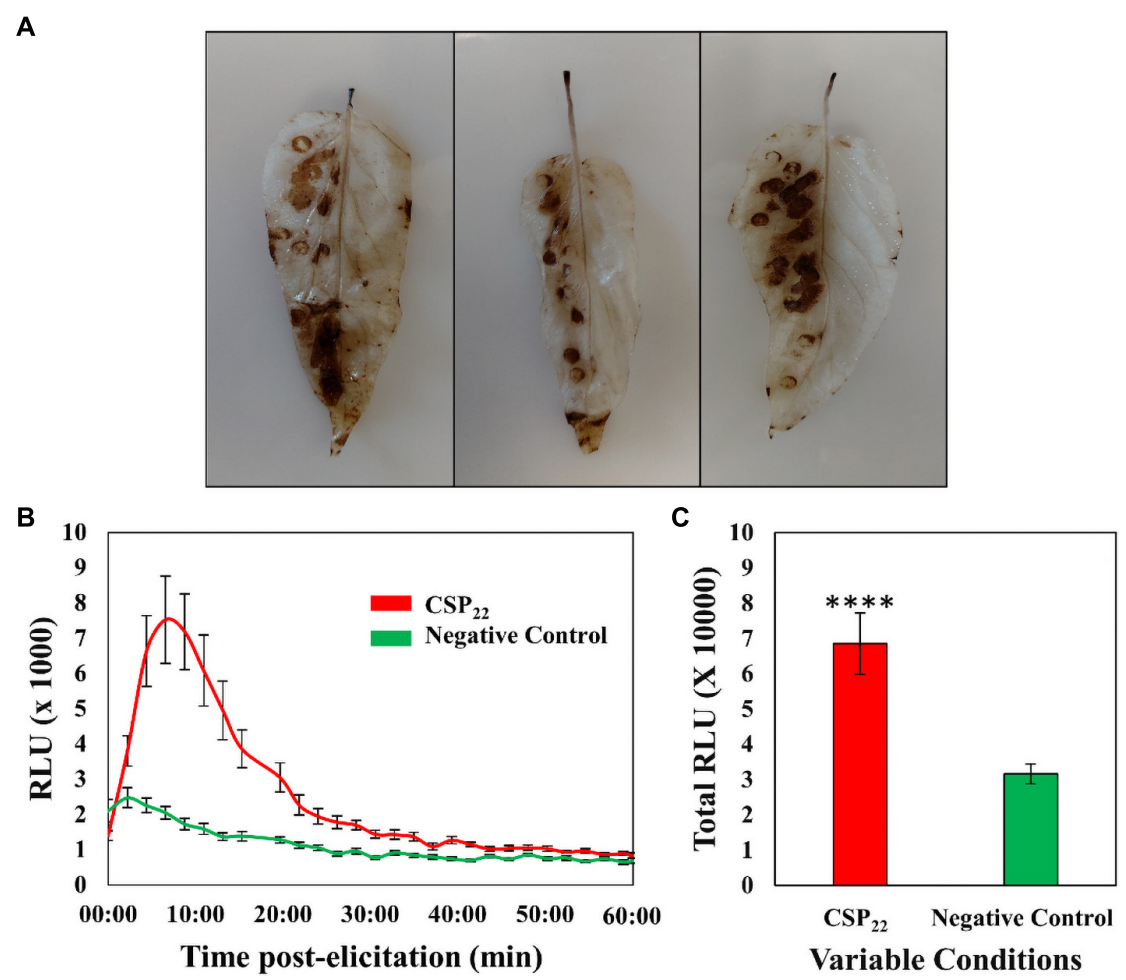

FIGURE 1 | The generation of reactive oxygen species in the leaf tissue of Solanum lycopersicum cv. Star 9001 in response to csp22 (500 nM) elicitation. (A) The generation of $\mathrm{H}_{2} \mathrm{O}_{2}$ visualized using the peroxidase-dependent histochemical stain 3,3-diaminobenzidine (DAB) after $24 \mathrm{~h}$ incubation at room temperature. The left abaxial half of the leaves was infused with the csp22 elicitor while the right abaxial half served as the negative control for comparative purposes. (B) The total ROS production during the oxidative burst over $60 \mathrm{~min}$ as indicated as the integrated area under the curve, described as $\Sigma$ relative luminescence units (RLU). The leaf disks were treated with a csp22 solution (red) and a negative $8 \mathrm{mM} \mathrm{MgSO}_{4}$ control (green). (C) The total kinetics of ROS production in 60 min after elicitor inoculation. Both experiments were replicated (DAB, $n=3$ and luminescence $n=24$ ), as three independent experiments. A pairwise Student's $t$-test was performed to determine statistical significance. The asterisks indicate the degree of statistical significance $\left(^{* * * *} p \leq 0.0001\right)$.

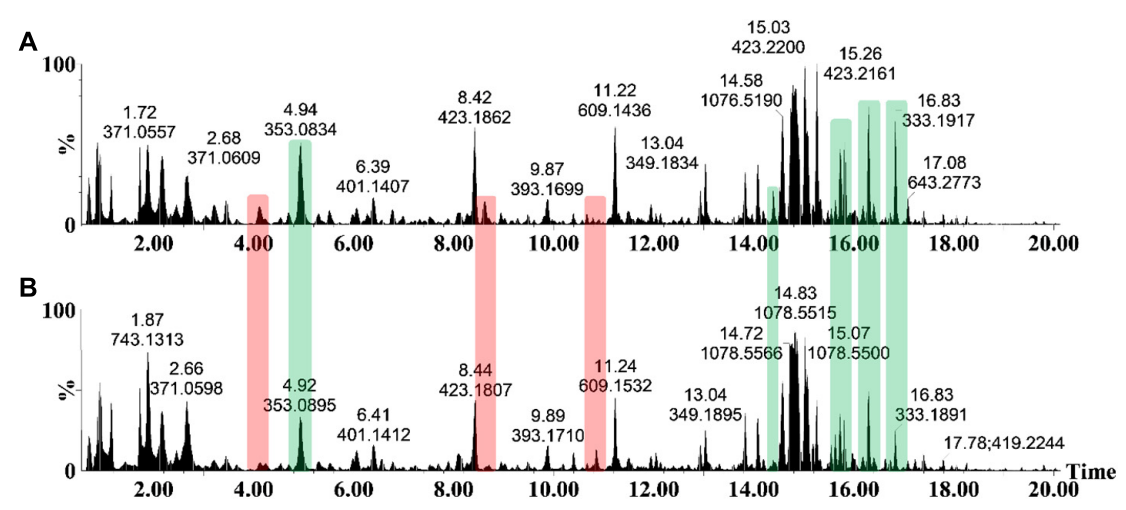

FIGURE 2 | The UHPLC-MS analyses of methanol extracts from the csp22-treated (500 nM) S. lycopersicum, Star 9001 cultivar. A comparison of the metabolite profiles at the $16 \mathrm{~h}$ time interval-(A) treatment and $\mathbf{( B )}$ control-revealed concentration-related variances in peak intensities. The $\mathrm{y}$-axis represents the relative abundance (\%) of the metabolite fragments at their respective retention times (min). Changes in peak intensities (green) and/or the presence/absence of peaks (red) reflect differential variation in elicitor-induced leaf metabolism.

and, (2) to subsequently reveal trends within the matrix that may be overlooked during PCA analysis. The HiCA model was constructed based on Ward's linkage method, considering distance clusters between- and within-samples. The PCA scores plot (Figure 3A) revealed the partial overlap between some of the observational groups e.g., the $32 \mathrm{~h}$ control and treated groups. The partial overlapping pattern observation could be attributed to a single immune-inducing elicitor treatment rather than a cocktail of elicitors frequently associated with live pathogen infection. The immune response produced by csp22-treatment 


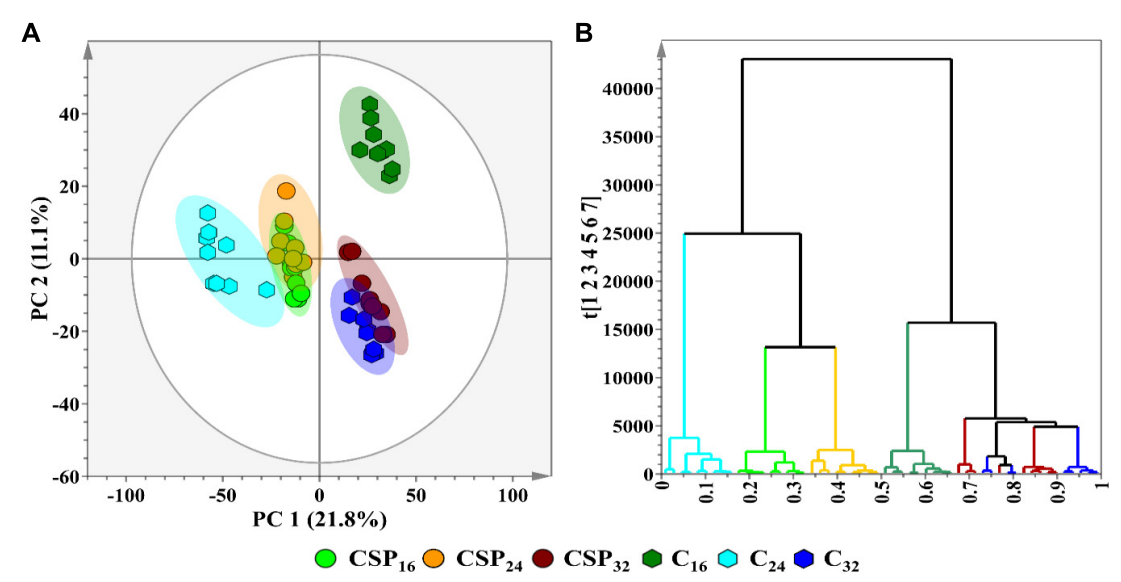

FIGURE 3 | A principal component analysis (PCA) score plot revealing the group clusters within the data matrices of S. lycopersicum extracts from leaf tissue after csp22 elicitor treatment at the incubation time points (16, 24, and $32 \mathrm{~h}$ ). (A) A 2D PCA scores plot illustrating the grouping of the observations. The PCA model had a calculated $R_{2} X$ (cum) value of $61.0 \%$ and a $Q_{2}$ (cum) value of $50.3 \%$. The ellipse on the score plot represents Hotelling's T2 with a $95 \%$ confidence interval. (B) A Ward-linkage hierarchical cluster analysis ( $\mathrm{HiCA}$ ) dendrogram corresponding to $\mathbf{( A )}$, showing the hierarchical outline of the data before and after treatment.

may leave the flux of some metabolic pathways unaffected resulting in metabolites with similar cellular levels in both the control and treated groups. This pattern of similarity in some metabolite classes may contribute to the partial overlapping pattern observed in the PCA scores plot.

In contrast to unsupervised learning methods that evaluate the patterns within data, supervised methods are designed for the prediction, classification and discovery of biomarkers (Ren et al., 2015). OPLS-DA models were constructed, as the selected supervised statistical method, to inform on class separation (Figure 4A). The statistical significance for the observed class separation in the OPLS-DA models were measured by calculating the cross-validated analysis of variance (CV-ANOVA) $p$-values, as a tuning method, applying a cut-off of $p<0.05$ (Trygg et al., 2007; Eriksson et al., 2008). The $p$-values of each computed supervised model were tabulated (Supplementary Table 1). The corresponding OPLS-DA loadings S-plot (Figure 4B) showed variables that were positively correlated to class separation, i.e., csp22 treatment at the selected incubation time points. These multidimensional analyses were then applied toward the identification of significant features to consider for annotation.

Discriminant features with a $\mid \mathrm{p}$ (corr) $\mid$ of $\geq 0.5$ and a co-variance value of $|(\mathrm{p} 1)| \geq 0.05$ were selected for further analysis (Trygg et al., 2007). These selection parameters were chosen based on the application of descriptive statistics (ANOVA) to the downstream metabolite features (Figure 4B), where a statistical cut-off of $p$-value $<0.05$ was used. This improved the selection of statistically relevant features, while simultaneously excluding the selection of false positives. The overall performance of the OPLS-DA models, in terms of selectivity, was assessed with the construction of a ROC curve (Figure 4C), showing that the supervised models, as binary classifiers, had perfect discrimination with regards to sensitivity and specificity (Supplementary Table 1). The predictive capacity of the supervised models was assessed with a $n=100$ response permutation test (Figure 4D; Eriksson et al., 2008). The permutation test revealed that the presented supervised models had higher calculated $R^{2}$ and $Q^{2}$-values (Supplementary Table 1 ) in comparison to the model permutations, concluding that the OPLS-DA model obtained was statistically superior to the generated permutations (Eriksson et al., 2008; Saccenti et al., 2014). The corresponding sets of figures for the 24 and $32 \mathrm{~h}$ time points are presented as Supplementary Figures 1, 2.

\section{Selection of Discriminant Features Based on Multivariate Statistical Analysis Data}

The OPLS-DA S-plot (Figure 4B) was used for the selection of metabolite features positively correlated to the elicitor treatment. The cut-off values of $\mid \mathrm{p}$ (corr) $\mid$ of $\geq 0.5$ and a co-variance value of $|(\mathrm{p} 1)| \geq 0.05$ were determined based on the application of univariate descriptive statistics (the calculation of control and treatment averaged peak intensities, the standard deviation, the coefficient of variation, fold change between the two groups, and the $p$-value) on the selected features. Descriptive statistics were used to provide basic information and summarize the characteristics of the variables between the samples from control and treated tissues. Metabolite features that were found to contain a $p$-value $>0.05$ and a coefficient of variation $>30$ were removed from the generated list of features. Using this process, the optimal values threshold values for $\mid p$ (corr) $\mid$ and |(p1)| were determined.

\section{Metabolite Investigation}

From 1,575 features (a combination of individual mass signals, including parental ions, isotopologs and possible MS fragments) initially acquired through ultra-high performance liquid chromatography coupled the mass spectrometry analyses, a total of 36 metabolites that were positively correlated to the csp22 treatment were putatively identified in the leaf tissue of S. lycopersicum (Table 1). The metabolites have been previously 

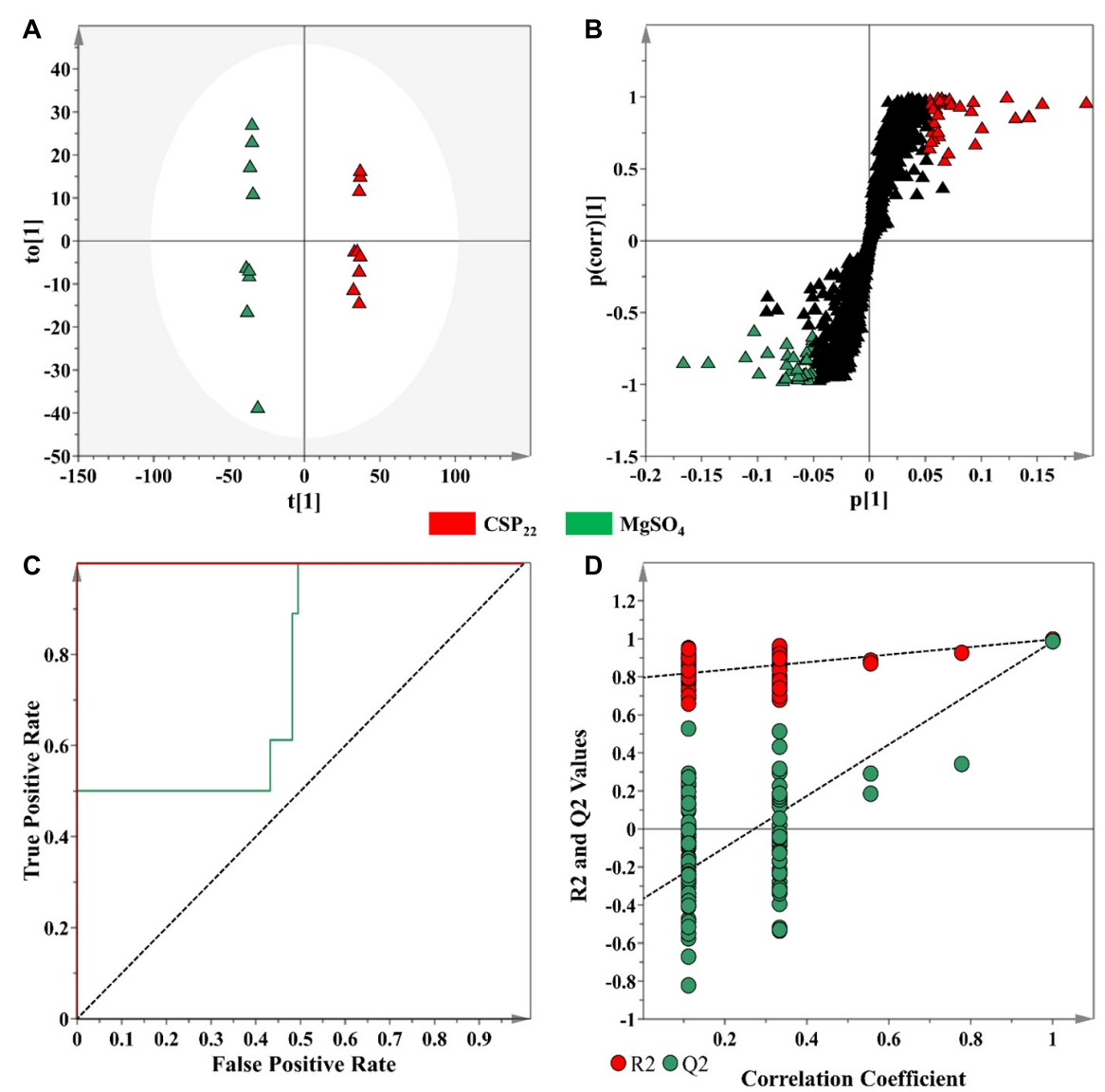

FIGURE 4 | An OPLS-DA model for data processing of methanol extracts from tomato leaf tissue at the $16 \mathrm{~h}$ incubation time. (A) An OPLS-DA scores plot showing the group separation of control vs. treated $\left(\mathrm{CSP}_{22}-\right.$ Green vs. $\left.\mathrm{MgSO}_{4}-\mathrm{Blue}\right)$ conditions. The calculated model yielded $\mathrm{R}^{2} \mathrm{X}(\mathrm{cum})=46.1 \%, \mathrm{R}^{2} \mathrm{Y}(\mathrm{cum})=99.7 \%$ and $\mathrm{Q}^{2}$ (cum) $=98.5 \%$. Model validation by 7-fold CV-ANOVA displayed a level of statistical significance with $p$-value $=8.502 \times 10^{-12}$. (B) The corresponding OPLS-DA loading S-plot. Relevant variables on the loadings S-plot (at the extremes, $x, y \geq 0.05,0.5$ ), were selected and represent potential discriminating variables. (C) A receiver operating characteristic $(\mathrm{ROC})$ curve summarizing the selective ability of a binary classifier (S-plot), with a classifier having a perfect discrimination producing a ROC curve that passes through the top left corner to indicate 100\% sensitivity and specificity. (D) The response permutation test plot ( $n=100)$ for the OPLS-DA model.

described in literature and databases related to tomato or plant species within the Solanaceae family. The metabolites were tabulated according to increasing Rt with corresponding $\mathrm{m} / \mathrm{z}$ values. Among the identified metabolites, several of the phytochemicals belong to the phenylpropanoid class (including cinnamates, benzoates, flavonoids and coumarins), conjugates such as amides of hydroxycinnamic acids (HCAs) and chlorogenic acids (CGAs), organic acids and amino acid derivatives and lipid classes. The metabolites were annotated based on: (1) accurate mass, utilized for calculating an empirical formula, (2) analysis of each compound's mass fragmentation, and (3) comparative analysis with existing literature.

Below, the structural elucidation of acetyl tryptophan rhamnoside (a deoxyhexoside) is shown, demonstrating the steps involved in metabolite annotation. Each metabolite's mass fragmentation pattern was investigated in both ionization modes, in conjunction with MS fragmentation at different energies $\left(\mathrm{MS}^{\mathrm{E}}\right)$, to illustrate how the MassFragment plugin of the MassLynx software facilitated the annotation of the fragment ions and verify the overall mass fingerprints. The elemental compositions of fragments were also calculated as a secondary method of validating each compound's structural identity (Figure 5).

\section{Semi-Quantitative Analysis of Metabolites}

The relative peak intensities of ferulic acid derivatives (feruloyl dopamine, feruloyl quinic acid and feruloyl hexoside) were compared between the $\mathrm{MgSO}_{4}$ control and csp22 elicitor treatments over the described incubation times (Figure 6). The data revealed that feruloyl dopamine biosynthesis (Figures 6A,B) was increased by a factor of $\geq 4$ throughout the 16,24 , and $32 \mathrm{~h}$ incubation intervals, with the overall production of the compounds peaking at the $24 \mathrm{~h}$ time point. This observed result overlaps with literature relating the tomato-Pseudomonas syringae pathosystem (Zacarés et al., 2007). Feruloyl quinic acid (Figures 6C,D) exhibited its highest cellular abundance (a fold increase of $\geq 8$ ) during the early $16 \mathrm{~h}$ time point which 
TABLE 1 | Annotation of metabolite signatures from the leaf tissue of S. lycopersicum displaying a positive correlation to the csp22 elicitor treatment at selected time intervals (16, 24, and $32 \mathrm{~h})$.

\begin{tabular}{|c|c|c|c|c|c|c|c|c|c|}
\hline$\#$ & $\begin{array}{l}\text { Retention } \\
\text { time (min) }\end{array}$ & Ionization & $m / z$ & $\begin{array}{c}\text { Putative } \\
\text { identification }\end{array}$ & $\begin{array}{l}\text { Chemical } \\
\text { formula }\end{array}$ & $\begin{array}{l}\text { Mass } \\
\text { error } \\
\text { (mDa) }\end{array}$ & $\begin{array}{l}\text { Mass } \\
\text { error } \\
\text { (ppm) }\end{array}$ & $\begin{array}{c}\text { Mass } \\
\text { fragmentation }\end{array}$ & $\begin{array}{l}\text { Metabolite } \\
\text { class }\end{array}$ \\
\hline 1 & 0.94 & {$[\mathrm{M}-\mathrm{H}]-$} & 191.019 & Citric acid & $\mathrm{C}_{6} \mathrm{H}_{8} \mathrm{O}_{7}$ & -0.2 & -1.0 & 173,111 & Organic acid \\
\hline 2 & 1.15 & {$[\mathrm{M}-\mathrm{H}]-$} & 191.019 & Isocitric acid & $\mathrm{C}_{6} \mathrm{H}_{8} \mathrm{O}_{7}$ & -0.2 & -1.0 & 173,111 & Organic acid \\
\hline 3 & 1.17 & {$[\mathrm{M}+\mathrm{H}]^{+}$} & 182.081 & Tyrosine & $\mathrm{C}_{9} \mathrm{H}_{11} \mathrm{NO}_{3}$ & -0.4 & -2.2 & 165,121 & Amino acid \\
\hline 4 & 3.03 & {$[\mathrm{M}+\mathrm{H}]^{+}$} & 188.069 & Indole acrylate & $\mathrm{C}_{11} \mathrm{H}_{9} \mathrm{NO}_{2}$ & -1.3 & -6.9 & 142 & Indole \\
\hline 5 & 3.22 & {$[\mathrm{M}-\mathrm{H}]-$} & 285.058 & Gentisate pentoside & $\mathrm{C}_{12} \mathrm{H}_{14} \mathrm{O}_{8}$ & -0.2 & -0.7 & 153 & Benzoic acid \\
\hline 6 & 3.45 & {$[\mathrm{M}-\mathrm{H}]-$} & 397.161 & $\begin{array}{c}\text { Benzoyl ornithine } \\
\text { hexoside }\end{array}$ & $\mathrm{C}_{18} \mathrm{H}_{26} \mathrm{~N}_{2} \mathrm{O}_{8}$ & 0.1 & 0.3 & 293,235 & Organic acid \\
\hline 7 & 4.12 & {$[\mathrm{M}-\mathrm{H}]-$} & 658.154 & GSH-CGA & $\mathrm{C}_{26} \mathrm{H}_{32} \mathrm{~N}_{3} \mathrm{O}_{15} \mathrm{~S}$ & -1.0 & -0.9 & $\begin{array}{c}515,466,385 \\
191\end{array}$ & $\begin{array}{l}\text { Glutathione } \\
\text { conjugate }\end{array}$ \\
\hline 8 & 4.70 & {$[\mathrm{M}-\mathrm{H}]-$} & 431.153 & $\begin{array}{l}\text { Benzyl alcohol } \\
\text { dihexoside }\end{array}$ & $\mathrm{C}_{19} \mathrm{H}_{28} \mathrm{O}_{11}$ & 0.3 & -0.9 & 269, 107 & Benzoic acid \\
\hline 9 & 4.91 & {$[\mathrm{M}-\mathrm{H}]-$} & 367.158 & $\begin{array}{l}\text { Dihydroxy-dimethoxy } \\
\text { prenylchalcone }\end{array}$ & $\mathrm{C}_{22} \mathrm{H}_{24} \mathrm{O}_{5}$ & 1.0 & 3.8 & $337,299,235$ & Flavonoid \\
\hline 10 & 4.94 & {$[\mathrm{M}-\mathrm{H}]-$} & 353.084 & Caffeoyl quinic acid & $\mathrm{C}_{16} \mathrm{H}_{18} \mathrm{O}_{9}$ & 0.3 & -7.9 & $191,179,135$ & CGA \\
\hline 11 & 4.99 & {$[\mathrm{M}+\mathrm{H}]^{+}$} & 217.098 & Cyclo methyltryptophan & $\mathrm{C}_{12} \mathrm{H}_{12} \mathrm{~N}_{2} \mathrm{O}_{2}$ & 0.1 & 7.5 & 143 & Indole \\
\hline 12 & 6.00 & {$[\mathrm{M}-\mathrm{H}]-$} & 293.121 & Eugenyl cinnamate & $\mathrm{C}_{19} \mathrm{H}_{18} \mathrm{O}_{3}$ & 0.8 & 2.7 & 147 & $\mathrm{HCA}$ \\
\hline 13 & 6.28 & {$[\mathrm{M}-\mathrm{H}]-$} & 355.101 & Feruloyl hexoside & $\mathrm{C}_{16} \mathrm{H}_{20} \mathrm{O}_{9}$ & -0.9 & -2.5 & 193 & $\mathrm{HCA}$ \\
\hline 14 & 6.79 & {$[\mathrm{M}-\mathrm{H}]-$} & 385.110 & Feruloyl glucaric acid & $\mathrm{C}_{16} \mathrm{H}_{18} \mathrm{O}_{11}$ & -1.1 & -2.9 & 223 & $\mathrm{HCA}$ \\
\hline 15 & 6.97 & {$[\mathrm{M}-\mathrm{H}]-$} & 385.075 & Sinapoyl hexoside & $\mathrm{C}_{17} \mathrm{H}_{22} \mathrm{O}_{10}$ & -0.6 & -1.6 & 209, 193 & HCA \\
\hline 16 & 7.31 & {$[\mathrm{M}-\mathrm{H}]-$} & 387.164 & $\begin{array}{l}\text { Hydroxyjasmonic acid } \\
\text { hexoside }\end{array}$ & $\mathrm{C}_{18} \mathrm{H}_{28} \mathrm{O}_{9}$ & -0.2 & -0.5 & 225 & $\begin{array}{c}\text { Phytohormone } \\
\text { derivative }\end{array}$ \\
\hline 17 & 8.62 & {$[\mathrm{M}-\mathrm{H}]-$} & 367.100 & Feruloyl quinic acid & $\mathrm{C}_{17} \mathrm{H}_{20} \mathrm{O}_{9}$ & -1.9 & -5.2 & 191,161 & CGA \\
\hline 18 & 8.66 & {$[\mathrm{M}+\mathrm{H}]^{+}$} & 177.054 & Methylumbelliferone & $\mathrm{C}_{10} \mathrm{H}_{8} \mathrm{O}_{3}$ & 0.1 & 0.6 & 161,106 & Coumarin \\
\hline 19 & 9.86 & {$[\mathrm{M}-\mathrm{H}]-$} & 393.165 & $\begin{array}{l}\text { Acetyl tryptophan } \\
\text { deoxyhexoside }\end{array}$ & $\mathrm{C}_{19} \mathrm{H}_{26} \mathrm{~N}_{2} \mathrm{O}_{7}$ & -0.6 & -1.5 & 245,203 & $\begin{array}{l}\text { Amino acid } \\
\text { derivative }\end{array}$ \\
\hline 20 & 10.91 & {$[\mathrm{M}+\mathrm{H}]^{+}$} & 695.365 & $\begin{array}{c}\mathrm{N}^{1}, \mathrm{~N}^{5}, \mathrm{~N}^{14} \text {-Tris- } \\
\text { (dihydro-caffeoyl) } \\
\text { spermine }\end{array}$ & $\mathrm{C}_{37} \mathrm{H}_{49} \mathrm{~N}_{4} \mathrm{O}_{9}$ & 0.4 & 0.6 & $\begin{array}{c}531,474,457 \\
293,222\end{array}$ & HCAA \\
\hline 21 & 10.99 & {$[\mathrm{M}-\mathrm{H}]-$} & 444.165 & $\begin{array}{c}\text { Coumaroyl tyramine } \\
\text { hexoside }\end{array}$ & $\mathrm{C}_{23} \mathrm{H}_{27} \mathrm{NO}_{8}$ & 0.2 & 0.5 & 282 & HCAA \\
\hline 22 & 11.22 & {$[\mathrm{M}-\mathrm{H}]-$} & 609.148 & Rutin & $\mathrm{C}_{27} \mathrm{H}_{30} \mathrm{O}_{16}$ & 2.0 & 3.3 & 463,301 & Flavonoid \\
\hline 23 & 11.75 & {$[\mathrm{M}-\mathrm{H}]-$} & 490.170 & $\begin{array}{l}\text { Feruloyl dopamine } \\
\text { hexoside }\end{array}$ & $\mathrm{C}_{24} \mathrm{H}_{29} \mathrm{NO}_{10}$ & 0.5 & 1.0 & 328 & HCAA \\
\hline 24 & 12.97 & {$[\mathrm{M}-\mathrm{H}]-$} & 328.118 & Feruloyl dopamine & $\mathrm{C}_{18} \mathrm{H}_{18} \mathrm{NO}_{5}$ & 0.3 & 0.9 & 177 & HCAA \\
\hline 25 & 13.73 & {$[\mathrm{M}-\mathrm{H}]-$} & 282.112 & Coumaroyl tyramine & $\mathrm{C}_{17} \mathrm{H}_{17} \mathrm{NO}_{3}$ & 0.9 & 3.2 & 147 & HCAA \\
\hline 26 & 13.98 & {$[\mathrm{M}+\mathrm{H}]^{+}$} & 792.599 & $\begin{array}{c}\text { Phosphatidyl choline } \\
\text { (16:0/22:6) }\end{array}$ & $\mathrm{C}_{46} \mathrm{H}_{82} \mathrm{NO}_{7} \mathrm{P}$ & 2.2 & 2.8 & 704,625 & Lipid \\
\hline 27 & 14.4 & {$[\mathrm{M}-\mathrm{H}]-$} & 453.23 & $\begin{array}{c}\text { Phosphatidyl glycerol } \\
\qquad(14: 1)\end{array}$ & $\mathrm{C}_{20} \mathrm{H}_{38} \mathrm{O}_{9} \mathrm{P}$ & 2.0 & 4.4 & $379,371,299$ & Lipid \\
\hline 28 & 15.26 & {$[\mathrm{M}-\mathrm{H}]-$} & 423.221 & $\begin{array}{c}\text { Phosphatidic acid } \\
\text { (8:0/8:0) }\end{array}$ & $\mathrm{C}_{19} \mathrm{H}_{37} \mathrm{O}_{8} \mathrm{P}$ & 5.2 & 12.3 & $\begin{array}{c}343,297,169 \\
89\end{array}$ & Lipid \\
\hline 29 & 15.26 & {$[\mathrm{M}-\mathrm{H}]-$} & 459.198 & $\begin{array}{c}\text { Cryptochlorophaeic } \\
\text { acid }\end{array}$ & $\mathrm{C}_{25} \mathrm{H}_{32} \mathrm{O}_{8}$ & -4.5 & -9.8 & $429,415,237$ & $\begin{array}{l}\text { Benzoic acid } \\
\text { derivative }\end{array}$ \\
\hline 30 & 15.33 & {$[\mathrm{M}-\mathrm{H}]-$} & 495.253 & $\begin{array}{l}\text { Hydroxycysteinylglycinyl } \\
\text { eicosatetraenoic acid }\end{array}$ & $\mathrm{C}_{25} \mathrm{H}_{40} \mathrm{~N}_{2} \mathrm{O}_{6} \mathrm{~S}$ & 1.9 & 3.7 & $\begin{array}{c}451,437,351 \\
177\end{array}$ & $\begin{array}{l}\text { Lipid/amino } \\
\text { acid derivative }\end{array}$ \\
\hline 31 & 15.59 & {$[\mathrm{M}-\mathrm{H}]-$} & 495.255 & $\begin{array}{l}\text { Hydroxycysteinylglycinyl } \\
\text { eicosatetraenoic acid }\end{array}$ & $\mathrm{C}_{25} \mathrm{H}_{40} \mathrm{~N}_{2} \mathrm{O}_{6} \mathrm{~S}$ & 2.1 & 4.2 & $\begin{array}{c}451,437,351 \\
177\end{array}$ & $\begin{array}{l}\text { Lipid/amino } \\
\text { acid derivative }\end{array}$ \\
\hline 32 & 15.92 & {$[\mathrm{M}+\mathrm{H}]^{+}$} & 537.252 & $\begin{array}{l}\text { Phosphatidyl glycerol } \\
\qquad(18: 1)\end{array}$ & $\mathrm{C}_{24} \mathrm{H}_{43} \mathrm{O}_{11} \mathrm{P}$ & 8.7 & 16.2 & - & Lipid \\
\hline 33 & 17.40 & {$[\mathrm{M}-\mathrm{H}]-$} & 327.214 & $\begin{array}{c}\text { Trihydroxy } \\
\text { octadecadienoic acid }\end{array}$ & $\mathrm{C}_{18} \mathrm{H}_{32} \mathrm{O}_{5}$ & -1.0 & -3.5 & 309 & Lipid \\
\hline
\end{tabular}

CGA, chlorogenic acid; HCA, hydroxycinnamic acid; HCAA, hydroxycinnamic acid amide.

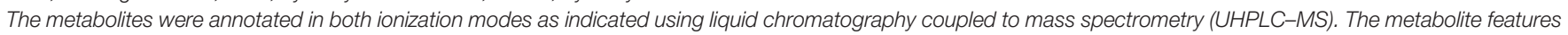
were annotated according to level 2 of the Metabolomics Standards Initiative (Sumner et al., 2007). 


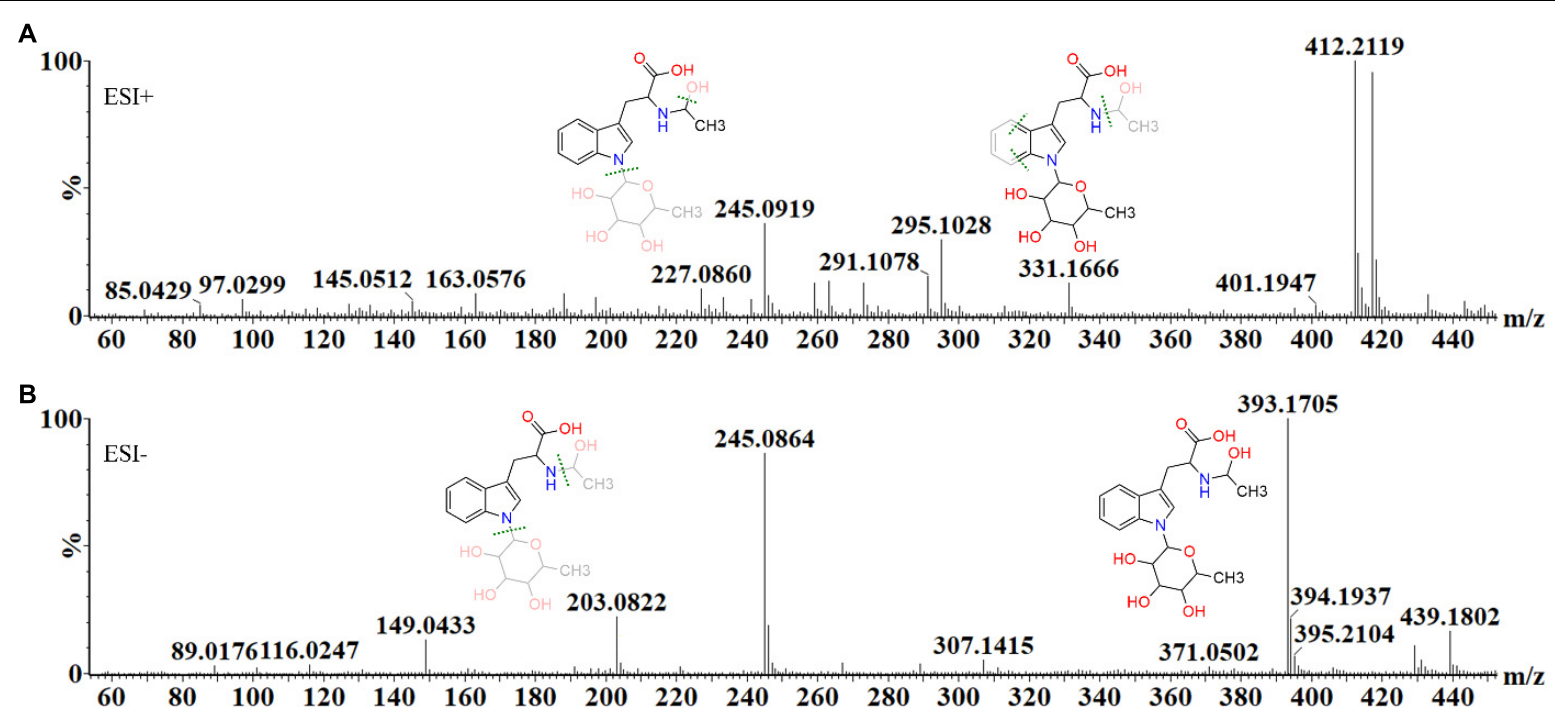

FIGURE 5 | The mass spectral fragmentation pattern of acetyl tryptophan deoxyhexoside $\left(\mathrm{C}_{19} \mathrm{H}_{26} \mathrm{~N}_{2} \mathrm{O}_{7}\right)$ in $(\mathbf{A})$ positive and (B) negative ionization modes. The MassFragment $\mathrm{XS}^{\mathrm{TM}}$ software, in conjunction with $\mathrm{MS}^{E}$, facilitated structural elucidation and compound identification, using the mass fragments in both ionization modes. In ESI (+) mode, the molecular ion is present as an adduct, $412.21\left[\mathrm{M}+\mathrm{H}_{+} \mathrm{NH}_{4}\right]^{+}$, while the main fragment ions are $145.05\left[\mathrm{M}+\mathrm{H}-\mathrm{C}_{13} \mathrm{H}_{18} \mathrm{~N}_{2} \mathrm{O}_{3}\right]^{+}, 163.06$ $\left[\mathrm{M}+\mathrm{H}_{+} \mathrm{C}_{10} \mathrm{H}_{18} \mathrm{NO}_{5}\right]^{+}, 227.09\left[\mathrm{M}+\mathrm{H}+\mathrm{C}_{6} \mathrm{H}_{16} \mathrm{O}_{5}\right]^{+}, 295.10\left[\mathrm{M}+\mathrm{H}_{-} \mathrm{C}_{14} \mathrm{H}_{17} \mathrm{NO}_{6}\right]^{+}$and $331.17\left[\mathrm{M}+\mathrm{H}-\mathrm{CH}_{4} \mathrm{O}_{3}\right]^{+}$. In ESI (-) mode, the precursor ion is 393.17 $[\mathrm{M}-\mathrm{H}]^{-}$, while the main fragment ions are $149.04\left[\mathrm{M}-\mathrm{H}-\mathrm{C}_{11} \mathrm{H}_{18} \mathrm{NO}_{5}\right]^{-}, 203.08\left[\mathrm{M}-\mathrm{H}_{-} \mathrm{C}_{8} \mathrm{H}_{14} \mathrm{O}_{5}\right]^{-}$and $245.09\left[\mathrm{M}-\mathrm{H}_{-} \mathrm{C}_{6} \mathrm{H}_{12} \mathrm{O}_{4}\right]^{-}, 307.14\left[\mathrm{M}-\mathrm{H}-\mathrm{C}_{7} \mathrm{H}_{2}\right]^{-}$and 439.18 $[\mathrm{M}-\mathrm{H}+\text { formic acid }]^{-}$.

slowly decreased to a new cellular homeostasis level during the 24 and $32 \mathrm{~h}$ intervals. A similar trend was observed with the feruloyl hexoside derivative (Figures 6E,F). The hexoside conjugate showed the highest cellular abundance in the leaf tissue at the $16 \mathrm{~h}$ time point with a fold increase of $\geq 2$. Following the $16 \mathrm{~h}$ time point, the levels of feruloyl hexoside decreased, returning to a newly established cellular homeostasis. The increased production of the feruloyl derivatives over the incubation period points to an elicitor-induced reprogramming at that occurs at the metabolome level. The observed trend indicates that the tomato leaf tissue produced most of its defenseassociated compounds during the $16 \mathrm{~h}$ time point that decrease, either by metabolite degradation or conversion, during the 24 and $32 \mathrm{~h}$ incubation points.

The relative abundance of the coumarin, methylumbelliferone was compared in the elicitor treatment and the $\mathrm{MgSO}_{4}$ control over the three incubation times (Figure 7A). The data indicates that methylumbelliferone production was increased up until the $16 \mathrm{~h}$ interval followed by a decline to a new cellular homeostasis. The metabolite's synthesis increased by a factor of $\geq 8$ during the $16 \mathrm{~h}$ incubation interval indicating an early involvement in the host immune response (Figure 7B).

Similarly, the cellular levels of the phytohormone derivative, hydroxyjasmonic acid hexoside, were also monitored between the two conditions over the incubation intervals (Figures 7C,D). The phytochemical displayed two cellular increases during the $16 \mathrm{~h}$ and $32 \mathrm{~h}$ intervals, with a drop in the overall abundance during the $24 \mathrm{~h}$ point (Figure $7 \mathrm{C}$ ). It should be noted that the metabolite levels at the $16 \mathrm{~h}$ time points, although statistically validated, demonstrated high levels of intra-sample variability. The jasmonic acid derivative showed $a \geq 2$-fold change during the $16 \mathrm{~h}$ interval followed by a delayed but more intense $\geq 4$-fold change in the $32 \mathrm{~h}$ interval (Figure 7D). A similar pattern was observed in the cellular levels of coumaroyl tyramine hexoside (Figures 7E,F). This HCA amide (HCAA) produced two statistically significant increases during the 16 and $32 \mathrm{~h}$ time intervals, while the $24 \mathrm{~h}$ point showed levels overlapping with the $\mathrm{MgSO}_{4}$ control. The compounds produced $\mathrm{a} \geq 2$-fold change during the $32 \mathrm{~h}$ time interval (Figure 7E).

\section{DISCUSSION}

Immune surveillance by the host involves an integrated network operating at different levels: MAMP perception and receptor activation, ROS production, calcium influx, activation of mitogen-activated protein kinase cascades, activation of $G$ proteins, activation of transcription factors, etc. The intensity and/or sustainability of the oxidative burst can be determining factors that affect down-stream signal transduction events and recent studies have shown that pathogens manipulate host redox signaling to shape the eventual plant-pathogen interaction (Bleau and Spoel, 2021).

The metabolome of a biological system provides a functional readout of the cellular state, thus serving as direct signatures of up-stream biochemical events that define the dynamic equilibrium of metabolism and the correlated phenotype. The possibility of applying progressively improved metabolomic tools and approaches in plant-microbe studies has opened new ways to investigate the intricate details of how plant metabolism is activated and re-directed upon immune activation (Mareya et al., 2019; Tugizimana et al., 2019). Previously we have utilized 

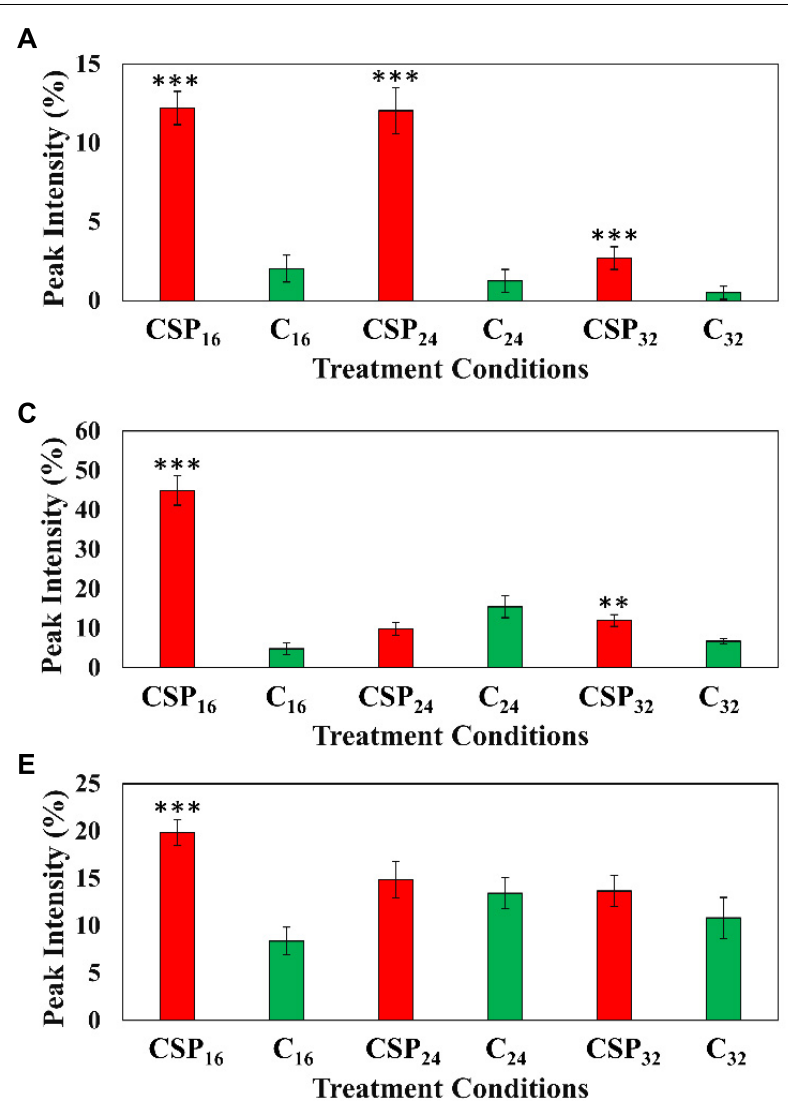

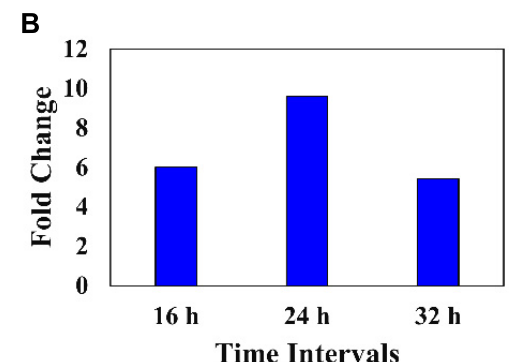

D
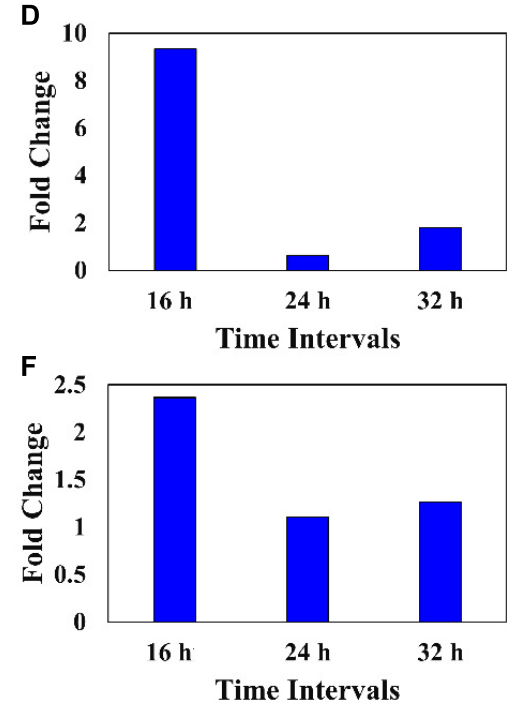

FIGURE 6 | Fluctuating levels of ferulic acid derivatives in S. lycopersicum at selected incubation times (16, 24, and 32 h-red) after treatment with the csp22 peptide. The relative peak intensities of (A) feruloyl dopamine, (C) feruloyl quinic acid, (E) feruloyl hexoside in the treated samples (red). The corresponding fold changes (B,D,F) are displayed (blue) at the described time intervals. A MgSO 4 control (C-green) was included for each time point as a comparative measure. Each data bar is presented as a mean value ( $\bar{x}$ of $n=9$ samples) with the error bars indicating the calculated standard deviation ( $\sigma$ ). A two-condition paired Student's $t$-test was performed to compare the treatments with the $\mathrm{MgSO}_{4}$ control where the asterisks indicate levels of statistical significance $(* * p \leq 0.001$, *** $p \leq 0.0001)$.

metabolomics for comparative metabolic phenotyping of tomato plants for the identification of metabolic signatures associated with different response capacities conferred by phenotypic plasticity in cultivars differing in resistance to $R$. solanacearum (Zeiss et al., 2018). Metabolomic profiling of the tomato host response following infection by $R$. solanacearum revealed that the phenylpropanoid pathway, represented by flavonoids and HCAs, acts as the central hub of induced defenses (Zeiss et al., 2019). Increased concentrations and variability of metabolites associated with defense pointed to cultivar-specific variation in the speed and manner of resource redistribution between the host tissues. Differential metabolic signatures were linked to the resistant vs. susceptible metabolic phenotypes, underlying the defense metabolism and defining their defensive capabilities to R. solanacearum (Zeiss et al., 2019).

In this study, the changes to the composition of the tomato leaf metabolome again reflects an inducible resistant phenotype in the host. A comparative summary of discriminant metabolites (that could be positively annotated), present in leaf extracts from tomato plants infected with $R$. solanacearum vs. those present in leaf extracts from csp22-treated plants, are presented in Figure 8. It is evident that the single elicitor was able to trigger the synthesis of only a subset of metabolites compared to that of the consortium of MAMPs that are present during infection with live bacteria. Interestingly, csp22 was also able to elicit metabolites that were not annotated in the data set corresponding to the R. solanacearum infection (Zeiss et al., 2019).

In general, plants seem to mobilize similar chemical defense responses as reflected by activation of similar pathways leading to secondary metabolite synthesis. At a metabolite level, this might be reflected in enhanced synthesis of secondary metabolites with antimicrobial and antioxidant activities. Moreover, plants execute the triggered defense based on the perceived stimulus and the existing biochemical background operative in the naïve vs. stress-related conditions. Allowing for the dynamic nature of plant metabolism, qualitative and quantitative differences of specific metabolites or classes of metabolites within the broader metabolomic profiles, may modulate the eventual outcome of a host response to attempted infection (Mhlongo et al., 2021). These molecules (Table 1 and discussed below) were found to accumulate in varying amounts in the csp22elicited leaves and exhibit differential accumulation patterns. These patterns indicate differential reprogramming over time (either high or low accumulation at specific time points, 

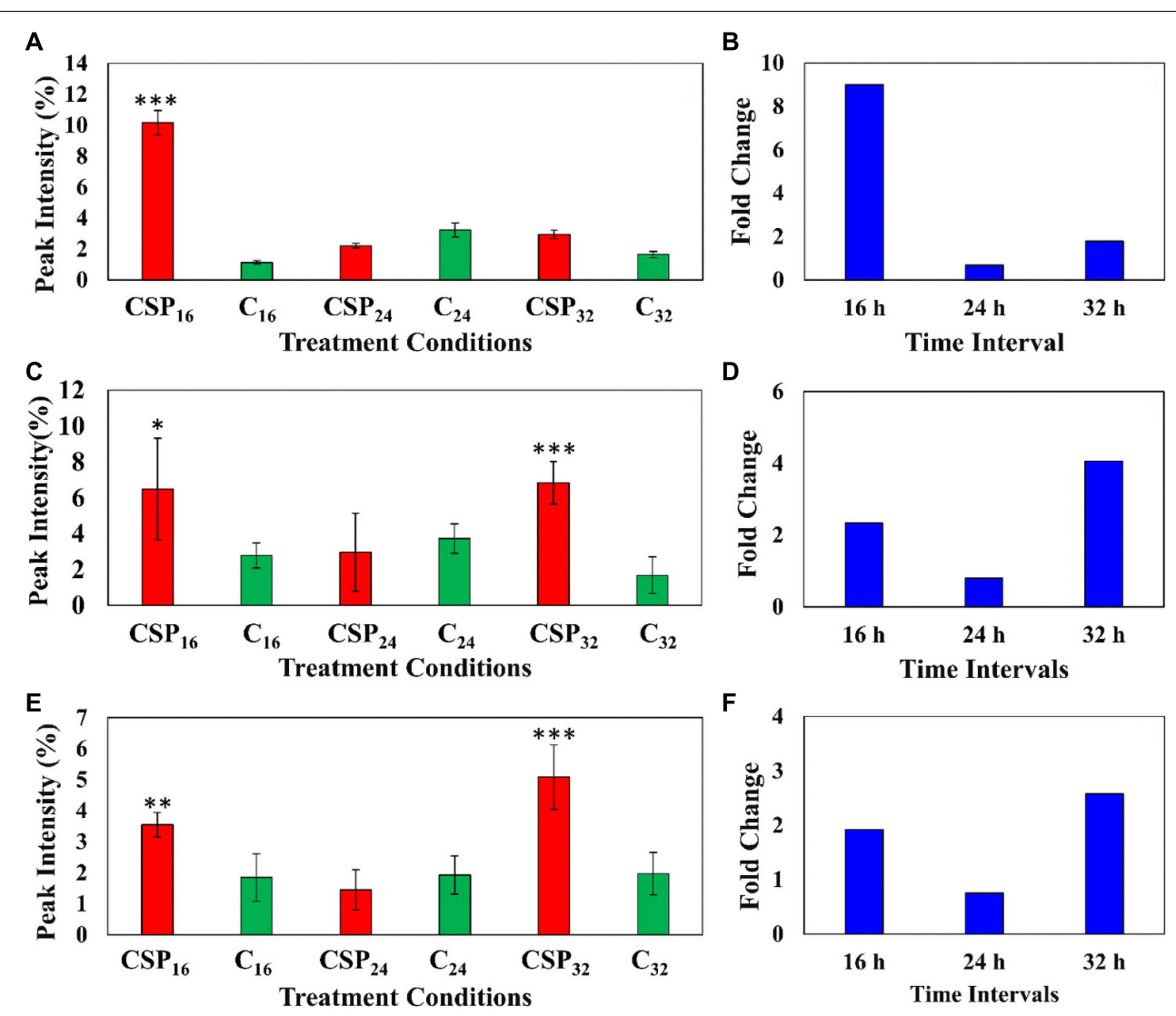

FIGURE 7 | Fluctuating levels of selected metabolites in S. lycopersicum at selected incubation times (16, 24, and 32 h-red) after treatment with the csp22 peptide. The relative peak intensities of $\mathbf{( A )}$ methylumbelliferone, (C) hydroxy jasmonic acid hexoside, (E) coumaroyl tyramine hexoside in the treated samples (red). The corresponding fold changes (B,D,F) are displayed (blue) at the described time intervals. $\mathrm{A} \mathrm{MgSO}_{4}$ control $(\mathrm{C}-$ green) was included for each time point as a comparative measure. Each data bar is presented as a mean value ( $\bar{x}$ of $n=9$ samples) with the error bars indicating the calculated standard deviation ( $\sigma$ ). A two-condition paired Student's $t$-test was performed to compare the treatments with the $\mathrm{MgSO}_{4}$ control where the asterisks indicate levels of statistical significance $\left(*=p \leq 0.01,{ }^{* *}=p \leq 0.001,{ }^{* * *}=p \leq 0.0001\right)$.

reflecting early-, late or oscillatory responses). The timedependent reprogramming is an indication that plants re-adjust their metabolomes toward defense responses in order to ward off infection (Mhlongo et al., 2021). In the absence of a real infection by $R$. solanacearum, the levels of the csp22-induced metabolites decrease again with the establishment of a new cellular homeostasis.

HCAs and-amides (HCAAs) (reviewed in Zeiss et al., 2021) are frequently associated with the metabolic stress responses of Solanaceous plants. In a comparative study of the effect of the MAMPs (lipopolysaccharides, chitosan, and flagellin22) on Nicotiana tabacum cells, overlapping metabolomes were found that indicate common aspects where the phenylpropanoid pathway (modulated by both salicylic acid and the methyl ester of jasmonic acid) is activated by these elicitors and where HCA derivatives are consequently synthesized (Mhlongo et al., 2016). The results generated from this untargeted metabolomics study revealed that csp22-elicitation lead to the production of several ferulic acid derivatives. This is believed to be the first report of csp22-induced accumulation of HCAAs in tomato. The increased production of feruloyl dopamine at the described incubation periods highlights a significance in the tomato metabolome. Several research publications have described the production of HCAAs, such as coumaroyl- and feruloyl tyramine, coumaroyl- and feruloyl dopamine, coumaroyl- and feruloyl noradrenaline (Figure 9), implicated as phytoalexins of tomato after infection with bacterial pathogens (Von Roepenack-Lahaye et al., 2003; Zacarés et al., 2007; López-Gresa et al., 2011; Zeiss et al., 2019). The exact biological function of these compounds has not yet been fully elucidated (Zeiss et al., 2021). It has, however, been shown that these small molecules possess strong antioxidant activity, with radical scavenging abilities comparable if not better than that of the synthetic antioxidant butylhydroxytoluene (López-Gresa et al., 2011). The HCAA feruloyl dopamine has been shown to have good antimicrobial activity against Pseudomonas syringae (Zacarés et al., 2007). The quantity of scientific research surrounding these compounds remains limited. Transgenic studies involving S. tuberosum using Arabidopsis transporter genes have revealed that the rapid secretion of HCAAs positively correlates to a decreased ability of Phytophthora infestans spore germination (Dobritzsch et al., 2016). 


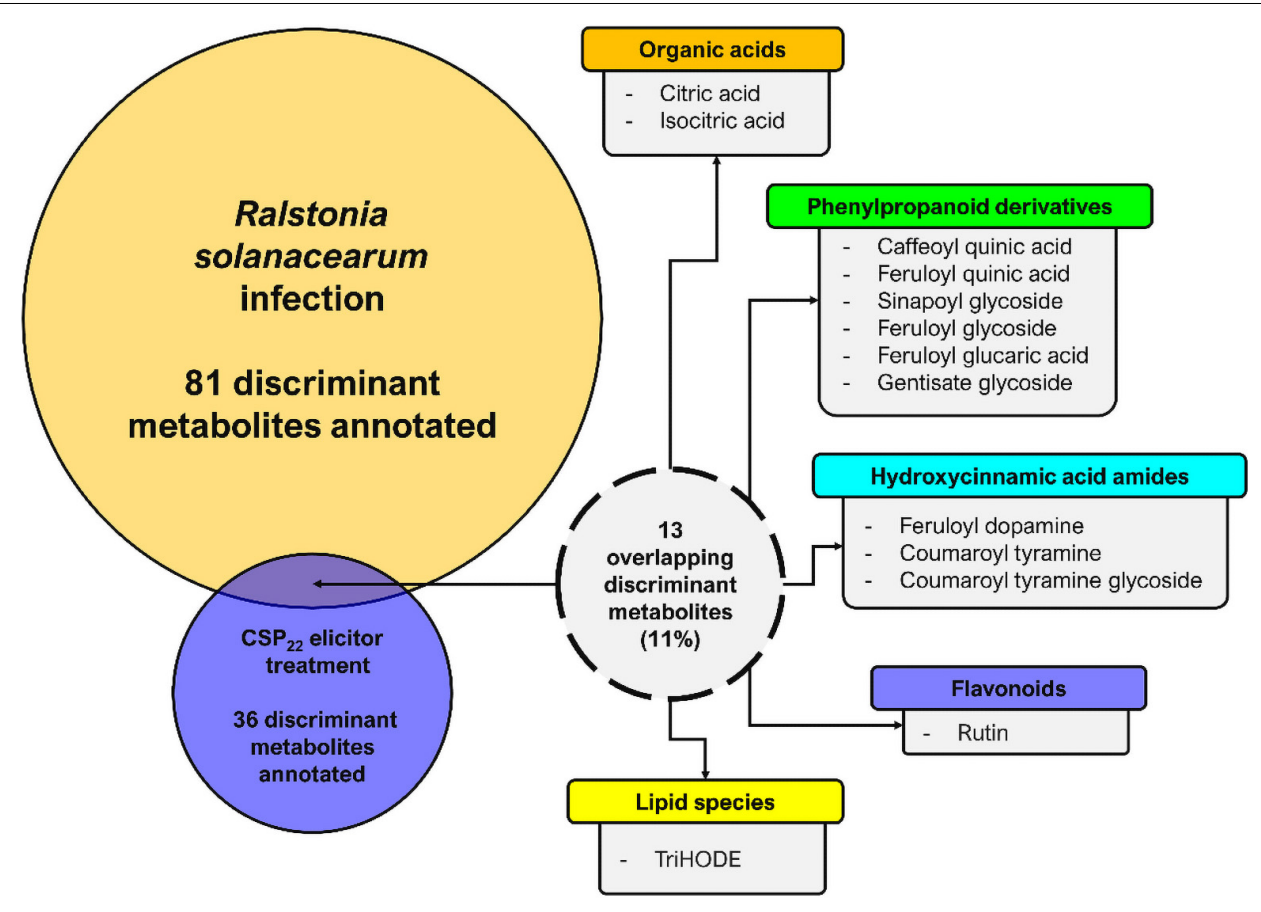

FIGURE 8 | Metabolome perturbations and adaptive defense responses. A Venn diagram highlighting the partial overlap (\%) of metabolites positively correlated to $R$. solanacearum and csp22 treatments in the leaf tissue of $S$. Iycopersicum. The numerical values represent the annotated metabolites that are unique to each treatment and conversely are also shared. It should be noted that the experimental conditions-including the biological, technical, instrumental, and laboratory performance aspects - for both publications were identical and could thus be compared (Zeiss et al., 2019, 2021).

Although caffeic acid and sinapic acid derivatives of HCAs were also amongst the identified variables, it is the HCA derivatives that carry a ferulic acid (o-methoxyphenol) substitution pattern that predominate: feruloyl hexoside, feruloyl glucaric acid, feruloyl quinic acid, feruloyl dopamine hexoside, feruloyl dopamine and eugenyl cinnamate. At an interactome level, from the pathogen's perspective, the production of ferulic acid and other HCA derivatives represents an obstacle that must be overcome to facilitate the early stages of infection and host colonization. HCA degradation is a conserved trait that shields R. solanacearum from the chemical defenses of the hosts to promote pathogen virulence (Lowe et al., 2015). The study demonstrated that mutants lacking the enzymes required for HCA degradation were less virulent on tomato plants and simultaneously more susceptible to cellular toxicity (Lowe et al., 2015). It should be noted that this trait is specifically directed toward the degradation of HCAs, rather than the HCAAs. In addition, literature has documented that umbelliferone may serve as a plant-derived inhibitor capable of attenuating the Type 3 secretion system (T3SS) of $R$. solanacearum in tobacco, suppressing transcription of T3SS regulators and effectors (Yang et al., 2017). The $R$. solanacearum virulence factors are tightly regulated by a complex interlocking network involving quorum sensing and plant signals (Schell, 2000; Mole et al., 2007). It has been shown that the rapid and timely expression of these genes is a crucial and conserved virulence strategy employed by the bacterial wilt pathogen (Jacobs et al., 2012). The hydroxycoumarin umbelliferone has been shown to inhibit the growth and development of Ralstonia strains on solid media in a concentration-based manner (Yang et al., 2018). The same study also demonstrated that tobacco root irrigation with hydroxycoumarins $24 \mathrm{~h}$ prior to pathogen challenge delayed symptoms typically associated with bacterial wilt (Yang et al., 2018). With tobacco and tomato being phylogenetic relatives, both belonging to the Solanaceae, it is feasible to suggest that tomato also utilizes umbelliferone, in conjunction with other phytochemicals, to act as protective agents in the management of $R$. solanacearum.

As discussed above, the changes to the composition of the tomato leaf metabolome speaks to the resistant phenotype of the host. Jasmonic acid (JA) and its associated derivatives have been reported to be produced during biotic perturbations as key regulators of plant defense leading to several alterations in metabolic pathways resulting in the biosynthesis of secondary metabolites (Okada et al., 2015; Mhlongo et al., 2016). JAmediated signaling pathways are linked to host resistance, prompting plant defense responses to external damage and pathogen infection, inducing gene expression typically observed in a resistant phenotype (Ruan et al., 2019). Hydroxylation and glycosylation are common steps used by plants to reduce or attenuate the bioactivity of particular metabolites in vivo. The finding of a hydroxyjasmonic acid derivative in the leaf extracts in response to csp22 elicitation thus indicates prior JA activity (Miersch et al., 2008; Hamany Djande et al., 2020) in the intracellular signaling cascade that leads to the production of defense-related compounds (e.g., the HCAAs). This can 


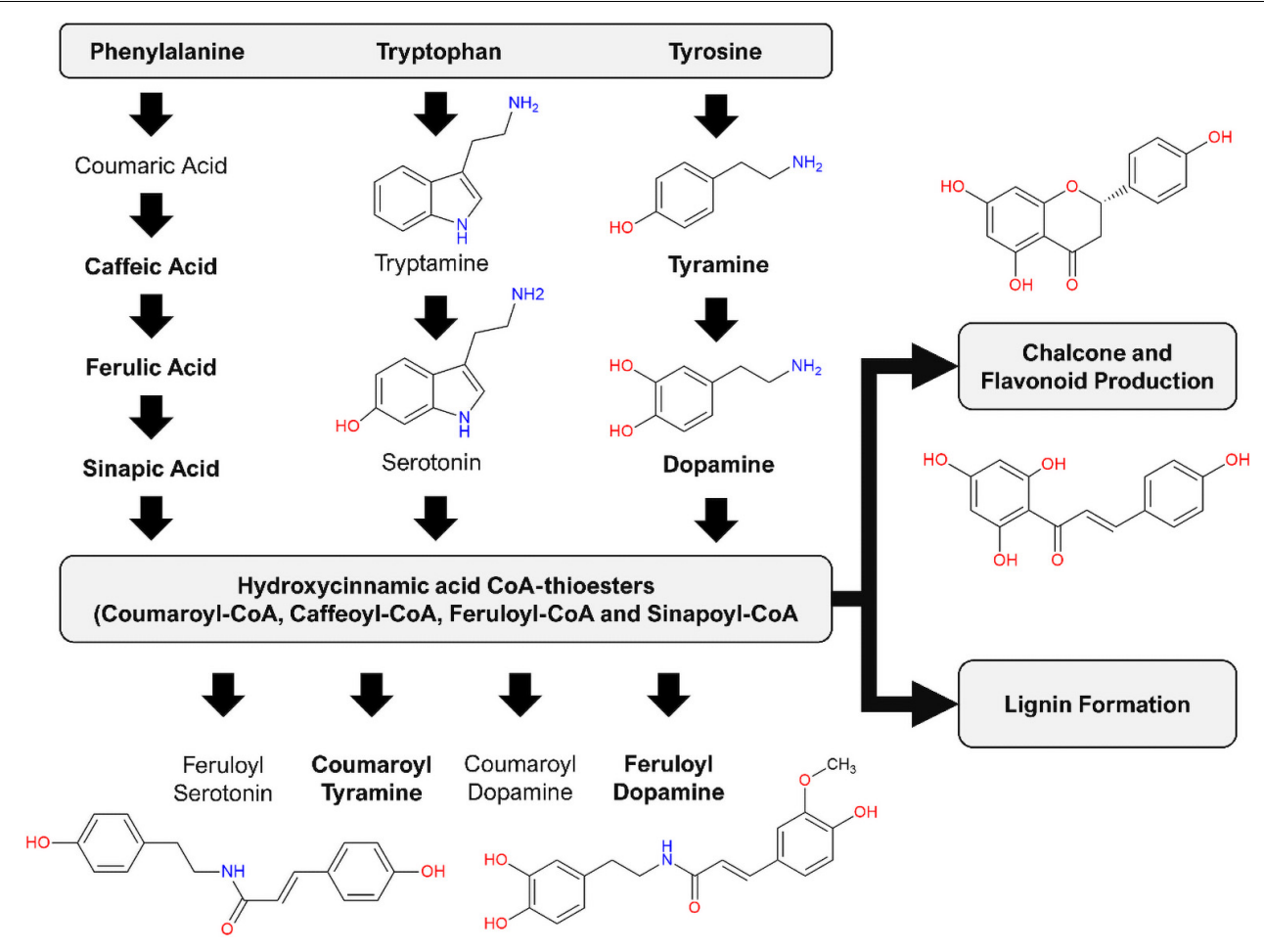

FIGURE 9 | Induced production of hydroxycinnamic acid amides (HCAAs) in the leaf tissue of S. lycopersicum in response to csp-22 elicitation. Biosynthesis starts with increased levels of the aromatic amino acids: flux from chorismate to prephenate (for phenylalanine and tyrosine) and anthranilate (for tryptophan). The synthesis of the HCAAs involves the amide conjugation of the aromatic amino acids to hydroxycinnamic acid CoA-thioesters. The HCA thioesters can also feed into downstream pathways leading to the production of flavonoid derivatives as well as the formation of lignin. Compound names in bold were found in the present study, while the remaining phytochemicals have been reported in other studies related to the Solanaceae.

contribute to the host plant displaying an accelerated and heightened state of plant defense. Using an untargeted approach, this upregulation of the JA- and coumaroyl tyramine derivatives could be observed over the 16,24 , and $32 \mathrm{~h}$ incubation intervals, bolstering the knowledge described in literature (Mhlongo et al., 2016). Based on the results obtained, it would be feasible to suggest that JA production induced by $\operatorname{csp} 22$ leads to a more resistant host phenotype that may be more equipped against future infection against a broad-spectrum of pathogens including R. solanacearum.

\section{CONCLUSION}

The results generated from this untargeted metabolomics study revealed that $\operatorname{csp} 22$ perception by leaf tissue of the tomato plant results in metabolome perturbation and the redirection of cellular metabolism to lead to the production of defensive and protective metabolites. This can be regarded as part of a functional metabolic strategy to cope with external environmental threats such as combating biotic stressors. These biochemical perturbations, primarily involving the phenylpropanoid pathway and sub-branches thereof, are linked to a csp22-triggered oxidative burst and associated downstream signal transduction events. The metabolites identified as signatory biomarkers include HCAs, HCAAs, and ferulic acid derivatives, emphasizing the role of the phenylpropanoid pathway as the central hub of induced defenses in tomato. Previous studies have associated the production of HCAAs (with antimicrobial and antioxidative properties) with biotic stress and elicitor treatments, and a dedicated function for these phytochemicals during plantpathogen interactions is starting to emerge. Furthermore, the csp22-induced production of the hydroxyjasmonic acid derivative bolsters evidence of the phytohormone's involvement in intracellular signaling that leads to the production of defenserelated compounds, contributing to an enhanced defensive capacity within the plant tissue. This heightened state may equip the host plant to better defend itself against present pathogen attack or future infection against a broad-spectrum of pathogens. These results, from a metabolomics perspective, thus support a role for csp22 treatment of tomato in order to increase resistance to $R$. solanacearum infection and contribute to greater insights into the mechanism of perception of $R$. solanacearum, aiding multi-omics approaches to generate resistance.

\section{DATA AVAILABILITY STATEMENT}

The datasets presented in this study can be found in online repositories. The names of the repository/repositories and accession number(s) can be found below: https://www.ebi.ac.uk/ metabolights/MTBLS3708. 


\section{AUTHOR CONTRIBUTIONS}

ID: conceptualization, funding acquisition, project administration, and supervision. DZ, PS, and ID: methodology and investigation. DZ: writing-original draft. ID and LP: writing-review and editing. All authors have read and agreed to the published version of the manuscript.

\section{FUNDING}

The University of Johannesburg is thanked for a "Global Excellence and Stature" (GES) fellowship to DZ Funding

\section{REFERENCES}

Bach-Pages, M., and Preston, G. M. (2018). Methods to quantify biotic-induced stress in plants. Methods Mol. Biol. 1734, 241-255. doi: 10.1007/978-1-49397604-1_19

Bleau, J. R., and Spoel, S. H. (2021). Selective redox signaling shapes plant-pathogen interactions. Plant Physiol. 186, 53-65. doi: 10.1093/plphys/kiaa088

Boller, T., and Felix, G. (2009). A renaissance of elicitors: perception of microbeassociated molecular patterns and danger signals by pattern-recognition receptors. Annu. Rev. Plant Biol. 60, 379-406. doi: 10.1146/annurev.arplant.57. 032905.105346

Castro-Moretti, F. R., Gentzel, I. N., Mackey, D., and Alonso, A. P. (2020). Metabolomics as an emerging tool for the study of plant-pathogen interactions. Metabolites 10, 1-23. doi: 10.3390/metabo10020052

Chen, H., Song, Q., Tang, G., Feng, Q., and Lin, L. (2013). The combined optimization of Savitzky-Golay smoothing and multiplicative scatter correction for FT-NIR PLS models. Hindawi Publ. Corp. 2013, 1-9.

Dobritzsch, M., Lübken, T., Eschen-Lippold, L., Gorzolka, K., Blum, E., Matern, A., et al. (2016). MATE transporter-dependent export of hydroxycinnamic acid amides. Plant Cell 28, 583-596. doi: 10.1105/tpc.15.00706

Dodds, P. N., and Rathjen, J. P. (2010). Plant immunity: towards an integrated view of plant-pathogen interactions. Nat. Rev. Genet. 11, 539-548. doi: 10.1038/ $\operatorname{nrg} 2812$

Eriksson, L., Trygg, J., and Wold, S. (2008). CV-ANOVA for significance testing of PLS and OPLS\$models. J. Chemom. 22, 594-600. doi: 10.1002/cem.1187

Freeman, B., and Beattie, G. (2008). An overview of plant defenses against pathogens and herbivores. Plant Pathol. Microbiol. 1, 1-12. doi: 10.1094/PHI-I2008-0226-01

Gómez-Romero, M., Segura-Carretero, A., and Fernández-Gutiérrez, A. (2010) Metabolite profiling and quantification of phenolic compounds in methano extracts of tomato fruit. Phytochemistry 71, 1848-1864. doi: 10.1016/j. phytochem.2010.08.002

Hamany Djande, C. Y., Madala, N. E., and Dubery, I. A. (2020). "Mass spectrometric approaches to study the metabolism of jasmonates: biotransformation of exogenously-supplemented methyl jasmonate by cell suspension cultures of Moringa oleifera," in Chapter 16 in Jasmonate in Plant Biology, Methods and Protocols, eds A. Champion and L. Laplaze (New York, NY: Springer Nature), 211-227. doi: 10.1007/978-1-0716-0142-6_16

Jacobs, J., Babujee, L., Meng, F., Milling, M., and Allen, C. (2012). The In Planta transcriptome of Ralstonia solanacearum: conserved physiological and virulence strategies during bacterial wilt of tomato. MBio 3, e00114-e00212. doi: 10.1128/mBio.00114-12

Keto-Timonen, R., Hietala, N., Palonen, E., Hakakorpi, A., and Lindström, M. (2016). Cold shock proteins: a minireview with special emphasis on csp-family of Enteropathogenic Yersinia. Front. Microbiol. 7:1151. doi: 10.3389/fmicb.2016. 01151

López-Gresa, M. P., Torres, C., Campos, L., Lisón, P., Rodrigo, I., Bellés, J. M., et al. (2011). Identification of defence metabolites in tomato plants infected by the bacterial pathogen Pseudomonas syringae. Environ. Exp. Bot. 74, 216-218. doi: $10.1016 /$ j.envexpbot.2011.06.003 from the South African National Research Foundation to ID (grant no. 95818) supported the research. The funder had no role in study design, data collection and analysis, decision to publish, or preparation of the manuscript.

\section{SUPPLEMENTARY MATERIAL}

The Supplementary Material for this article can be found online at: https://www.frontiersin.org/articles/10.3389/fpls.2021. 803104/full\#supplementary-material

Lowe, T. M., Ailloud, F., and Allen, C. (2015). Hydroxycinnamic acid degradation, a broadly conserved trait, protects Ralstonia solanacearum from chemical plant defenses and contributes to root colonization and virulence. Mol. Plant Microbe Interact. 28, 286-297. doi: 10.1094/MPMI-09-14-0292-FI

Malik, N. A. A., Kumar, I. S., and Nadarajah, K. (2020). Elicitor and receptor molecules: orchestrators of plant defense and immunity. Int. J. Mol. Sci. 21, 1-33. doi: 10.3390/ijms21030963

Mansfield, J., Genin, S., Magori, S., Citovsky, V., Sriariyanum, M., Ronald, P., et al. (2012). Top 10 plant pathogenic bacteria in molecular plant pathology. Mol. Plant Pathol. 13, 614-629. doi: 10.1111/J.1364-3703.2012.00804.X

Mareya, C. R., Tugizimana, F., Piater, L. A., Madala, N. E., Steenkamp, P. A., and Dubery, I. A. (2019). Untargeted metabolomics reveal defensome-related metabolic reprogramming in Sorghum bicolor against infection by Burkholderia andropogonis. Metabolites 9:8. doi: 10.3390/metabo9010008

Mhlongo, M. I., Piater, L. A., Madala, N. E., Steenkamp, P. A., and Dubery, I. A. (2016). Phenylpropanoid defences in Nicotiana tabacum cells: overlapping metabolomes indicate common aspects to priming responses induced by lipopolysaccharides, chitosan and flagellin-22. PLoS One 11:e0151350. doi: 10. 1371/journal.pone.0151350

Mhlongo, M. I., Piater, L. A., Steenkamp, P. A., Labuschagne, N., and Dubery, I. A. (2021). Metabolomic evaluation of tissue-specific defense responses in tomato plants modulated by PGPR-priming against Phytophthora capsici infection. Plants 10:1530. doi: 10.3390/plants10081530

Miersch, O., Neumerkel, J., Dippe, M., Stenzel, I., and Wasternack, C. (2008). Hydroxylated jasmonates are commonly occurring metabolites of jasmonic acid and contribute to a partial switch-off in jasmonate signaling. New Phytol. 177, 114-127. doi: 10.1111/j.1469-8137.2007.02252.x

Mole, B. M., Baltrus, D. A., Dangl, J. L., and Grant, S. R. (2007). Global virulence regulation networks in phytopathogenic bacteria. Trends Microbiol. 15, 363 371. doi: 10.1016/j.tim.2007.06.005

Okada, K., Abe, H., and Arimura, G. I. (2015). Jasmonates induce both defense responses and communication in monocotyledonous and dicotyledonous plants. Plant Cell Physiol. 56, 16-27. doi: 10.1093/pcp/pcu158

Ranf, S. (2018). Pattern recognition receptors-versatile genetic tools for engineering broad-spectrum disease resistance in crops. Agronomy 8:134. doi: 10.3390/agronomy8080134

Ren, S., Hinzman, A. A., Kang, E. L., Szczesniak, R. D., and Lu, L. J. (2015). Computational and statistical analysis of metabolomics data. Metabolomics 11 1492-1513. doi: 10.1007/s11306-015-0823-6

Roldan, M. V. G., Engel, B., De Vos, R. C. H., Vereijken, P., Astola, L., Groenenboom, M., et al. (2014). Metabolomics reveals organ-specific metabolic rearrangements during early tomato seedling development. Metabolomics 10, 958-974. doi: 10.1007/s11306-014-0625-2

Ruan, J., Zhou, Y., Zhou, M., Yan, J., Khurshid, M., Weng, W., et al. (2019). Jasmonic acid signaling pathway in plants. Int. J. Mol. Sci. 20:2479. doi: 10.3390/ ijms20102479

Saccenti, E., Hoefsloot, H. C. J., Smilde, A. K., Westerhuis, J. A., and Hendriks, M. M. W. B. (2014). Reflections on univariate and multivariate analysis of metabolomics data. Metabolomics 10, 361-374. doi: 10.1007/s11306-0130598-6 
Sanabria, N. M., Huang, J. C., and Dubery, I. A. (2012). Self/non-self perception in plants in innate immunity and defense. Self Nonself 1, 40-54. doi: 10.1007/9781-4614-1680-7

Saur, I. M. L., Kadota, Y., Sklenar, J., Holton, N. J., Smakowska, E., Belkhadir, Y., et al. (2016). NbCSPR underlies age-dependent immune responses to bacterial cold shock protein in Nicotiana benthamiana. Proc. Natl. Acad. Sci. U.S.A. 113, 3389-3394. doi: 10.1073/pnas.1511847113

Schell, M. A. (2000). Control of virulence and pathogenicity genes of Ralstonia solanacearum by an elaborate sensory network. Annu. Rev. Phytopathol. 38, 263-292. doi: 10.1146/annurev.phyto.38.1.263

Spicer, R. A., Salek, R., and Steinbeck, C. (2017). A decade after the metabolomics standards initiative its time for a revision. Sci. Data 4:170138. doi: 10.1038/ sdata. 2017.138

Sumner, L. W., Amberg, A., Barrett, D., Beale, M. H., Beger, R., Daykin, C. A., et al. (2007). Proposed minimum reporting standards for chemical analysis chemical analysis working group (CAWG) metabolomics standards inititative (MSI). Metabolomics 3, 211-221. doi: 10.1007/s11306-007-0082-2. Proposed

Triba, M., Moyec, L., Le Amathieu, R., Goossens, C., Bouchemal, N., Nahon, P., et al. (2014). PLS/OPLS models in metabolomics: impact of permutation of dataset rows on the K-fold cross validation quality parameters. Mol. Biosyst. 11, 13-19. doi: $10.1039 / \mathrm{c} 4 \mathrm{mb} 00414 \mathrm{k}$

Trygg, J., Holmes, E., and Lundstedt, T. (2007). Chemometrics in metabonomics. J. Proteome Res. 6, 469-479. doi: 10.1021/pr060594q

Tugizimana, F., Djami-Tchatchou, A. T., Steenkamp, P. A., Piater, L. A., and Dubery, I. A. (2019). Metabolomic analysis of defence-related reprogramming in Sorghum bicolor in response to Colletotrichum sublineolum infection reveals a functional metabolic web of phenylpropanoid and flavonoid pathways. Front. Plant Sci. 9:1840. doi: 10.3389/fpls.2018.01840

Tugizimana, F., Mhlongo, M. I., Piater, L. A., and Dubery, I. A. (2018). Metabolomics in plant priming research: the way forward? Int. J. Mol. Sci. 19:1759. doi: 10.3390/ijms19061759

Tugizimana, F., Piater, L., and Dubery, I. (2013). Plant metabolomics: a new frontier in phytochemical analysis. S. Afr. J. Sci. 109, 18-20.

Tugizimana, F., Steenkamp, P. A., Piater, L. A., and Dubery, I. A. (2016). A conversation on data mining strategies in LC-MS untargeted metabolomics: pre-processing and pre-treatment steps. Metabolites 6, 1-18. doi: 10.3390/ metabo6040040

Von Roepenack-Lahaye, E., Newman, M., Schornack, S., Hammond-Kosack, K. E., Lahaye, T., Jones, J. D. G., et al. (2003). P-Coumaroylnoradrenaline, a novel plant metabolite implicated in tomato defense against pathogens. J. Biol. Chem. 278, 43373-43383. doi: 10.1074/jbc.M305084200

Wang, L., Albert, M., Einig, E., Fürst, U., Krust, D., and Felix, G. (2016). The pattern-recognition receptor CORE of Solanaceae detects bacterial cold-shock protein. Nat. Plants 2:16185. doi: 10.1038/NPLANTS.2016.185

Wei, Y., Balaceanu, A., Rufian, J. S., Segonzac, C., Zhao, A., Morcillo, R. J. L., et al. (2020). An immune receptor complex evolved in soybean to perceive a polymorphic bacterial flagellin. Nat. Commun. 11:3763. doi: 10.1038/s41467$020-17573-y$
Wei, Y., Caceres-moreno, C., Jimenez-Gongora, T., Wang, K., Sang, Y., LozanoDuran, R., et al. (2018). The Ralstonia solanacearum csp22 peptide, but not flagellin-derived peptides, is perceived by plants from the Solanaceae family. Plant Biotechnol. J. 16, 1349-1362. doi: 10.1111/pbi.12874

Yang, L., Li, S., Qin, X., Jiang, G., Chen, J., Li, B., et al. (2017). Exposure to umbelliferone reduces Ralstonia solanacearum biofilm formation, transcription of type III secretion system regulators and effectors and virulence on tobacco. Front. Microbiol. 8:1234. doi: 10.3389/fmicb.2017.01234

Yang, L., Wu, L., Yao, X., Zhao, S., Wang, J., Li, S., et al. (2018). Hydroxycoumarins: new, effective plant-derived compounds reduce Ralstonia pseudosolanacearum populations and control tobacco bacterial wilt. Microbiol. Res. 215, 15-21. doi: 10.1016/j.micres.2018.05.011

Zacarés, L., López-Gresa, M. P., Fayos, J., Primo, J., Bellés, J. M., and Conejero, V. (2007). Induction of $p$-coumaroyldopamine and feruloyldopamine, two novel metabolites, in Tomato by the bacterial pathogen Pseudomonas syringae. Mol. Plant Microbe Interact. 20, 1439-1448. doi: 10.1094/MPMI-20-11-1439

Zeiss, D. R., Mhlongo, M. I., Tugizimana, F., Steenkamp, P. A., and Dubery, I. A. (2018). Comparative metabolic phenotyping of tomato (Solanum lycopersicum) for the identification of metabolic signatures in cultivars differing in resistance to Ralstonia solanacearum. Int. J. Mol. Sci. 19:2558. doi: 10.3390/ijms19092558

Zeiss, D. R., Mhlongo, M. I., Tugizimana, F., Steenkamp, P. A., and Dubery, I. A. (2019). Metabolomic profiling of the host response of tomato (Solanum lycopersicum) following infection by Ralstonia solanacearum. Int. J. Mol. Sci. 20:3934. doi: 10.3390/ijms20163945

Zeiss, D. R., Piater, L. A., and Dubery, I. A. (2021). Hydroxycinnamate amides: intriguing conjugates of plant protective metabolites. Trends Plant Sci. 26, 184-195. doi: 10.1016/j.tplants.2020.09.011

Zhou, B., Xiao, J. F., Tuli, L., and Ressom, H. W. (2012). LC-MS-based metabolomics. Mol. Biosyst. 8, 470-481. doi: 10.1039/c1mb05350g.LC-MSbased

Zipfel, C. (2014). Plant pattern-recognition receptors. Trends Immunol. 35, 345351. doi: $10.1016 /$ j.it.2014.05.004

Conflict of Interest: The authors declare that the research was conducted in the absence of any commercial or financial relationships that could be construed as a potential conflict of interest.

Publisher's Note: All claims expressed in this article are solely those of the authors and do not necessarily represent those of their affiliated organizations, or those of the publisher, the editors and the reviewers. Any product that may be evaluated in this article, or claim that may be made by its manufacturer, is not guaranteed or endorsed by the publisher.

Copyright (c) 2022 Zeiss, Steenkamp, Piater and Dubery. This is an open-access article distributed under the terms of the Creative Commons Attribution License (CC BY). The use, distribution or reproduction in other forums is permitted, provided the original author(s) and the copyright owner(s) are credited and that the original publication in this journal is cited, in accordance with accepted academic practice. No use, distribution or reproduction is permitted which does not comply with these terms. 